\title{
TOWARDS THERMOELECTRIC NANOSTRUCTURED ENERGY HARVESTER \\ FOR WEARABLE APPLICATIONS
}

*In the memory of Dr Andy Cranny, a dedicated scientist and a good friend

E Koukharenko $^{1}$, S A Boden ${ }^{1}$, N P Sessions ${ }^{2}$, N Frety ${ }^{4}$, I Nandhakumar ${ }^{3}$, and N M White ${ }^{1}$ 1 School of Electronics and Computer Science, University of Southampton, Highfield, Southampton, SO17 1BJ, UK

2 Optoelectronics Research Centre, University of Southampton, Highfield, Southampton, SO17 1BJ, UK

3 School of Chemistry, University of Southampton, Highfield, Southampton, SO17 1BJ, UK 4 Institut Charles Gerhardt-Equipe PMOF Université Montpellier II, France

Corresponding author. E-mail address: $\underline{\text { ak@ecs.soton.ac.uk }}$ 


\section{Abstract}

Thermoelectric (TE) devices provide a clean and environmentally friendly technique for energy conversion. There is, however, limited published research addressing the optimal design and fabrication of flexible thermoelectric generators (TEGs), which use nanostructured materials and can conform to the contours of the geometry on which they are mounted. This paper describes a novel technological route that was found to be a promising approach for realising nanostructured energy harvesters on flexible substrates operating at small temperature gradients $<20 \mathrm{~K}$ and suitable for wearable applications. By comparison, current commercial rigid TEGs operate at temperature gradients of $50-70 \mathrm{~K}$.

The fabrication process reported here requires a combination of traditional silicon microfabrication techniques, electroplating and ion-track nanolithography. Polyimide nanotemplates, with pore diameters ranging from $30 \mathrm{~nm}$ to $120 \mathrm{~nm}$ and a high aspect ratio (1:1000), were fabricated from Kapton foil with a thickness of $20 \mu \mathrm{m} . \mathrm{Bi}_{2} \mathrm{Te}_{3}$ and $\mathrm{Bi}_{0.5} \mathrm{Sb}_{1.5} \mathrm{Te}_{3}$ nanowires (80 to $120 \mathrm{~nm}$ ) were successfully electrodeposited into such templates. Both compounds had optimal microstructural properties for thermoelectric applications. While $\mathrm{Bi}_{2} \mathrm{Te}_{3}$ (n-type element) films had a close-to-stoichiometric composition $\left(\mathrm{Bi}_{2.17} \mathrm{Te}_{2.81}\right), \mathrm{Bi}_{0.5} \mathrm{Sb}_{1.5} \mathrm{Te}_{3}$ (p-type element) samples exhibited significant deviations from their stoichiometric composition (from $\mathrm{Bi}_{0.37} \mathrm{Sb}_{1.44} \mathrm{Te}_{3.20}$ to $\mathrm{Bi}_{0.29} \mathrm{Sb}_{1.43} \mathrm{Te}_{3.27}$.

\section{Keywords}

thermoelectric generator, nanowires, flexible, ion-track nanolithography, polyimide, wearables, high aspect ratio 


\section{Introduction}

The energy requirements for modern societies, together with emerging ecological concerns, are constantly expanding. Additionally, the rapid increase in the development of remote wireless devices, embedded structures and portable electronic systems, illustrates the need for localised energy sources, such as batteries, which tend to be bulky, need replacement and have a limited shelf life. An alternative approach is to replace these by harvesting energy from ambient sources existing within the environment (e.g. solar, wind, vibration and thermoelectric). Thermoelectric power generation presents many advantages over other principles including solid-state operation (no moving parts), long life ( 20 years), high reliability and no emission of toxic gases [1].

The major drawbacks of existing thermoelectric generators are their low efficiency (commercially available devices have an efficiency of $\sim 10 \%$ ) and their relatively large size. As an example, typical electrical power output from mainstream commercial TE generators is about 2.1 W from a $\sim 3800 \mathrm{~mm}^{3}$ device, which requires a temperature gradient in excess of 70 ${ }^{\circ} \mathrm{C}[2]$.

To date, the smallest thin film-based miniaturised chip-level thermogenerators have been manufactured by Micropelt. A preliminary data sheet for these devices, which still require further testing, shows that they have a volume of $\sim 1400 \mathrm{~mm}^{3}$ device and produce $\sim 2$ $6 \mathrm{~mW}$ power for a temperature gradient between $20-30 \mathrm{~K} \mathrm{[3].}$

Importantly, at the present moment in time, existing commercial technologies for TE generators are only suitable for manufacturing onto rigid substrates, which can cause limitations for some possible application areas (e.g. rigid substrates are not well suited for wearable applications since they cannot conform to the required curved geometrical contours). Consequently, a strategy for improving the performance of TE devices, as well as a 
development of flexible thermoelectric energy harvesters, which are compatible with wearable technologies is needed.

The efficiency of thermoelectric (TE) materials is described by the figure of merit $\mathrm{ZT}=\left(\alpha^{2} \mathrm{~T} / \rho \mathrm{KT}\right)$, where $\alpha, \mathrm{T}, \rho$ and $\mathrm{KT}$ are the Seebeck coefficient, absolute temperature, electrical resistivity and thermal conductivity respectively [1]. In order to maximize ZT of a material, a high thermopower (absolute value of the Seebeck coefficient), high electrical conductivity, and low thermal conductivity are required. Therefore, the performance of these devices depends on the properties of the materials. The best TE materials commercially available today are $\mathrm{Bi}_{2-\mathrm{x}} \mathrm{Sb}_{\mathrm{x}} \mathrm{Te}_{3}$ based which have a $\mathrm{ZT}$ of $\sim 1$ at room temperature. However, nanostructured materials have recently attracted great interest because theoretical analysis indicates that greatly improved efficiency can be obtained by realising nanoscale thermoelectric (TE) elements whose 'leg' diameter can be reduced in size to that at which quantum confinement and interface scattering effects will occur [4, 5 ].

To date, various research groups have dedicated their work to either investigating physical properties of various TE nanostructures or developing technologies for miniaturized TE devices. Venkatasubramian et al. studied nanostructured thin-film superlattices of $\mathrm{Bi}_{2} \mathrm{Te}_{3}$ and $\mathrm{Sb}_{2} \mathrm{Te}_{3}$ and found that they exhibited $\mathrm{ZT} \sim 2.4$ at room temperature [6 ]. Hoffmann et al. reported on the thermoelectric power of InSb quantum-dot structures [7]. Boukai et al. and Hochbaum et al. investigated properties of $\mathrm{Si}$ nanowires and demonstrated that they show promise as high-performance, scalable thermoelectric materials [8, 9]. Shi et al. and Lyeo et al. measured physical properties of a single wall carbon nanotube bundle, BiTe nanowires and a GaAs p-n junction $[10,11,12]$. Zou et al observed an enhancement of ZT as high as 1.34 in thin GaAs nanowires of a $1.1 \mathrm{~nm}$-diameter, exhibiting more than 100 -fold improvement over the bulk counterpart [13] 
As far as fabrication processes for thermoelectric devices are concerned, to date $\mathrm{Bi}_{2}$ ${ }_{x} \mathrm{Sb}_{\mathrm{x}} \mathrm{Te}_{3}$ nanostructures are being focused on and various traditional fabrication methods, such as laser ablation, solution-based synthesis, vapour-phase growth, thermal evaporation methods, and vacuum-based techniques (e.g. metal organic vapour deposition (MOVPD), molecular beam epitaxy (MBE)) $[14,15,16,17,18]$ have been developed. All of these techniques require a complex parameter optimisation process and most of them are not compatible with silicon microfabrication processes and/or are very expensive. Hence there is currently great interest in alternative template-based synthesis to miniaturize thermoelectric materials using micro/nano-templates from porous alumina, micro/nanophotolithography [19, $20,21,22]$. Although these technologies offer some unique advantages of precise size and shape control to fabricate nanowires, they still have limitations in size, and can be complex for parameter optimisation, resulting in a low density of thermoelectric elements and lowefficiency devices [23]. The current state-of-the-art MEMS thermoelectric devices fabricated by a template technology, i.e. electroplating and photolithography, were presented by Snyder et al., resulting in a total device volume of about $8000 \mathrm{~mm} 3$ and a maximum generated power of about $1 \mu \mathrm{W}$ for a thermal gradient of $\sim 3^{\circ} \mathrm{C} / \mu \mathrm{m}$ over a thickness of $20 \mu \mathrm{m}$ [20]. Whilst this is a promising start and enough to power devices such as wristwatches, it is not sufficient for many of today's wireless sensor applications. More recently, the fabrication of $\mathrm{Bi}$ and $\mathrm{Bi}_{2-}$ ${ }_{x} \mathrm{Sb}_{\mathrm{x}} \mathrm{Te}_{3}(\mathrm{x}=1.5)$ thermoelectric nanowires has been realised with alternative templates using ion-track irradiation lithography $[24,25,26,27]$. This technique uses heavy accelerated ions to damage a material, making it susceptible to chemical etching in the direction defined by the irradiation. It has been discovered that ion-track technology can produce low-cost templates for nanowires with a diameter $<50 \mathrm{~nm}$ and with high aspect ratios $(>1000)$, which opens up a very promising technology for the fabrication of TE nanostructured devices [28]. Another advantage of this technology is that it can be integrated as a part of standard silicon 
microfabrication batch processes by using conventional UV-type photoresists such as polyimide and PMMA (Poly(methyl methacrylate)) [ 29, 30 ]. To date, however, ion-track technology has shown promising potential, but it has not been sufficiently explored for devices and has not become an application- driven technology.

In general, currently, there is a limited amount of published research dedicated to the development of thermoelectric nanostructured generators on flexible substrates, which offer not only a low-cost approach for depositing materials but can also expand the areas of wearable applications (where any curved geometry and non-planar shapes are present). The current state-of-the-art for the miniaturized thermoelectric devices onto flexible substrates has been limited to studies done either with low-efficiency thermoelectric materials (e.g. polymer composites; metal dichalcogenide ) [31, 32], or microstructured/nanostructured Bi-Sb-Te fabricated by costly processes with the power outputs which is well below useful levels [33, 34]. Ya Yang et al developed a complex architecture for a flexible thermoelectric nanogenerator (TENG) that is based on a Te-nanowire/poly(3-hexylthiophene) (P3HT) polymer composite as the thermoelectric material, which under a temperature difference of $55 \mathrm{~K}$, two TENGs can provide an output voltage of $38 \mathrm{mV}$ in serial connection, or a current density exceeding $32 \mathrm{nA} / \mathrm{mm} 2$ in parallel connection. [31]

Wan et al developed flexible n-type thermoelectric materials by organic intercalation of layered transition metal dichalcogenide TiS2, which could potentially find application in wearable electronics with further optimisation, although the thermoelectric figure of merit, ZT, is only 0.28 at $373 \mathrm{~K}[32]$.

Goncalves et al. developed $\mathrm{Bi}_{2} \mathrm{Te}_{3}$ and $\mathrm{Sb}_{2} \mathrm{Te}_{3}$-based thermoelectric micro-coolers on a Kapton flexible substrate using thermal co-evaporation and shadow-masking, which is a very time consuming and challenging process with difficulties in obtaining stochiometric compounds [35]. Qu et al. reported a TE generator, with overall dimensions of $16 \times 20 \times 0.05$ 
mm using Bi-Sb thermocouples on a flexible epoxy substrate, which produced an electrical output of 8.4 mVK-1 [36].

Francioso et al built a flexible $\mathrm{Sb}_{2} \mathrm{Te}_{3}$ and $\mathrm{Bi}_{2} \mathrm{Te}_{3}$-based microthermoelectric generator $(\mu \mathrm{TEG})$ for wearable biometric sensors applications, which consisted of an array of 100 thin film thermocouples with microscale features. It generates an open circuit output voltage of $430 \mathrm{mV}$ and an electrical output power up to $32 \mathrm{nW}$ for a thermal gradient of $40{ }^{\circ} \mathrm{C}$ into a matched electrical load [37]. Du et al developed thermoelectric fabrics by using organic thermoelectric material EDOT:PSS, where device can generate thermoelectric voltage output of $4.3 \mathrm{mV}$ at a temperature difference (DT) of $75.2 \mathrm{~K} .[38]$

None of the above studies have addressed the development of TE generators fabricated onto flexible substrates using $\mathrm{Bi}-\mathrm{Sb}$-Te nanostructures and a template based approach.

Thus, the objective of the present work is a technological development for a thermoelectric nanostructured device on a flexible polyimide substrate, which is suitable for wearable applications. In order to achieve this, a combination of silicon microfabrication techniques and ion-track nanolithography is used. In addition, this research addresses several material science challenges associated with optimization of electroplating parameters for submicron $\mathrm{Bi}_{2} \mathrm{Te}_{3}$ and $\mathrm{Bi}_{0.5} \mathrm{Sb}_{1.5} \mathrm{Te}_{3}$ nanowires (30-120 nm diameters), deposited into high aspect ratio polyimide nanostructured templates. It also reports nano/microstructural properties (phase analysis, chemical composition and grain size) and physical properties (Hall effect, Seebeck coefficient) as well as the influence of annealing on the performance of thermoelectric materials. Preliminary test results of such flexible TE polyimide-based nanostructured device are also presented. 


\section{Experimental procedure}

\subsection{Microfabrication process}

In order to realize the thermoelectric nanostructured generator, a 4-mask micromachining process was developed. The fabrication process can be summarised in the following way: The optimum processes and material parameters have been identified in our earlier work $[24,26]$. Polyimide foils, $\sim 20 \mu \mathrm{m}$ thick (dry films of Kapton HN from Dupont) are exposed to the ion track irradiation and wet etched, resulting in the required nanotemplate consisting of high density $\left(5 \times 10^{19}\right.$ pores $\left./ \mathrm{cm}^{2}\right)$ parallel tracks for nanowires electroplating (fig 1a). A thin layer of $\mathrm{Cr} / \mathrm{Au}(20 \mathrm{~nm} / 200 \mathrm{~nm})$ is evaporated onto the underside of the polyimide foil, patterned using standard photolithography and plasma etching to define the bottom electrode pattern (1c) to act as a seed layer for future n-type $\mathrm{Bi}_{2} \mathrm{Te}_{3}$ and $\mathrm{p}$-type $\mathrm{Bi}_{0.5} \mathrm{Sb}_{1.5} \mathrm{Te}_{3}$ electroplating (fig 1e, fig 1g). These particular compounds have been selected as they are known to be the best negative (n-type) and positive (p-type) compositions for thermoelectric applications around room temperature [1]. Selective electroplating for $n$ - and $p$-type materials is defined by a photolithographic process. In particular, next photolithographic step defined the template area for n-type $\mathrm{Bi}_{2} \mathrm{Te}_{3}$ electroplating (fig 1d) where the remaining surface of the nanotemplate is covered by photoresist to prevent electroplating there. The n-type $\mathrm{Bi}_{2} \mathrm{Te}_{3}$ metal nanowire structure will be then electroplated onto the $\mathrm{Cr} / \mathrm{Au}$-seed layer and filling the Kapton's mould (fig 1e). A subsequent photolithographic step is then defined the template area for p-type $\mathrm{Bi}_{0.5} \mathrm{Sb}_{1.5} \mathrm{Te}_{3}$ electroplating (fig 1f). The p-type $\mathrm{Bi}_{2-\mathrm{x}} \mathrm{Sb}_{\mathrm{x}} \mathrm{Te}_{3}$ metal nanowire structure will then be electroplated (fig 1g). Finally, an aluminium layer is evaporated and patterned to form the upper interconnect layers between individual TE elements (figure 1e). The polyimide template is then can be removed, 'freeing' the $\mathrm{Bi}_{2} \mathrm{Te}_{3}$ and BiSbTe nanoelements. Kapton can be successfully removed by using an NMP (N-methylpyrrolidone)-based solvent. Since the structural stability of the device is affected, a flexible version of the generator can be 
produced by leaving the low thermal conductivity polyimide film as the main structural support. The fabrication process is diagrammatically illustrated in Fig. 1.

Fig. 1: Process flow of a thermoelectric microgenerator on a flexible substrate

\subsection{Polyimide Nanotemplates etching}

All polyimide samples $(20 \mu \mathrm{m}$ thick Kapton $\mathrm{HN}$ films from Dupont $)$ were irradiated with $\mathrm{Pb}$ projectiles of $\sim 2.3 \mathrm{GeV}$ kinetic energy and fluences of $5 \times 10^{9}$ ions $/ \mathrm{cm}^{2}$ at the heavy ion accelerator Unilac at the GSI (Darmstadt). Irradiated samples were pre-etched in $\mathrm{H}_{2} \mathrm{O}_{2}$ solution at $60^{\circ} \mathrm{C}$ or $90^{\circ} \mathrm{C}$ and subsequently etched in sodium hypochlorite $(\mathrm{NaClO}, 13 \%, \mathrm{pH} 12.6)$ solution at $60^{\circ} \mathrm{C}$.

\subsection{Bi-Sb-Te nanowires electroplating}

Electroplating of $\mathrm{Bi}_{2} \mathrm{Te}_{3}$ and $\mathrm{Bi}_{0.5} \mathrm{Sb}_{1.5} \mathrm{Te}_{3}$ nanowires into polymide templates was carried out by cathodic electrochemical co-deposition of bismuth and tellurium powder dissolved in aqueous nitric acid using a three-electrode cell with an Autolab potentiostat/galvanostat $[39,40]$. It was found that the electrodeposition conditions (such as current density, deposition potential and temperature) have a significant effect on the $\mathrm{Bi}_{2} \mathrm{Te}_{3}$ and $\mathrm{Bi}_{0.5} \mathrm{Sb}_{1.5} \mathrm{Te}_{3}$ nanostructure and morphology. The samples were electrodeposited in the plating bath at room temperature. While $\mathrm{Bi}_{2} \mathrm{Te}_{3}$ compounds were deposited at a range of applied potentials from $-0.22 \mathrm{~V}$ to $0.03 \mathrm{~V}$ vs. a Saturated Calomel Electrode (SCE), $\mathrm{Bi}_{0.5} \mathrm{Sb}_{1.5} \mathrm{Te}_{3}$ films were electroplated between $-0.06 \mathrm{~V}$ and $-0.15 \mathrm{~V}$ vs. SCE [40].

\subsection{Bi-Sb-Te nanowires liberation}

After electrodeposition, the polyimide foils are removed by dissolution in organic solvent mixtures of NMP (N-methylpyrrolidone)/MEA (monoethanol-amine) from Sigma Aldrich. Various NMP/MEA compositions (wt \%) were prepared prior selecting an optimal ratio for nanowires liberation. However, NMP/MEA compositions (wt \%) of 90/10 and 30/70 were identified as the most promising. The NMP/MEA solutions were first well mixed with 
magnetic stirrers for about 20 min to ensure a uniform polyimide template dissolution process. Polyimide foils with embedded nanowires were then placed into vials with the NMP/MEA organic solvent mixture at room temperature, which then was heated up to around $95{ }^{\circ} \mathrm{C}$.

\subsection{Bi-Sb-Te nanowires microstructural characterization}

The grain size of the $\mathrm{Bi}_{2} \mathrm{Te}_{3}$ and $\mathrm{Bi}_{0.5} \mathrm{Sb}_{1.5} \mathrm{Te}_{3}$ nanowires were characterized using a JSM$6500 \mathrm{~F}$ scanning electron microscope $(\mathrm{SEM})$ operated at $20 \mathrm{kV}$. The crystal structure of the nanowires was investigated using a Siemens D5000 X-ray diffractometer with $\mathrm{Cu} \mathrm{K}_{\alpha}$ radiation $(\lambda=1.5406 \AA$ ). In addition, helium ion microscopy (HIM) [41, 42] was performed using a Carl Zeiss Orion Plus helium ion microscope, operated with a beam energy of 28.4 $\mathrm{keV}$ and a working distance of $7.1 \mathrm{~mm}$. A conductive coating was not needed because an integrated electron flood gun was used to neutralize charge accumulation to enable high contrast imaging of the electrically-insulating sample [43]. The chemical composition of $\mathrm{Bi}_{2} \mathrm{Te}_{3}$ and $\mathrm{Bi}_{0.5} \mathrm{Sb}_{1.5} \mathrm{Te}_{3}$ films and nanowires was determined using EDS (energy dispersive spectrometry) with an accuracy of measurement of $\sim 5 \%$. The analysed volume was of the order of $\mu \mathrm{m}^{3}$ from the surface. Since this analysis provides an approximate value for chemical composition due to its measurement error, the elemental composition for the films was also investigated by microprobe analysis (Cameca, Castaing) to refine the results. Microprobe provides $\sim 0.1 \%$ in the accuracy of the measurements for heavy elements and the analysed volume corresponded to a thickness of the order of $1 \mu \mathrm{m}$ from the film surface. In addition, this technique allows the study of the homogeneity of the chemical composition across the film surface, which is an important parameter for thermoelectric performance [49].

\subsection{Thermoelectric performance of electroplated thin film structures}


The Seebeck coefficient $\alpha(\mu \mathrm{V} / \mathrm{K})$ was determined using a custom-made Seebeck measurement unit, which was calibrated against a reference standard. A differential method of thermopower measurements was used: the temperature difference $\Delta \mathrm{T}$ between two points of the sample and the potential difference $\Delta U$ between the same two points were measured when the net current in the sample was zero, $\mathrm{J}=0$. Therefore, the electrical field in the sample is due to the Seebeck effect only, $\mathrm{E}=\alpha \cdot \Delta \mathrm{T}$. Copper-constantan thermocouples were positioned directly onto the sample surface at "cold" and "hot" sides.

The Seebeck coefficients measurements were in-plane measurements and performed on the complete thin electroplated films. A schematic diagram of the of the Seebeck coefficients measurements set-up showing electrical connexions as well as the picture of the actual equipment are illustrated in Fig 2. The measurements were carried out as follows: a heated probe, whose tip is a thermocouple junction (type $\mathrm{T}$ - Copper-constantan, $\mathrm{Cu}-\mathrm{CuNi}$ ) is placed directly onto the surface of a sample measuring the temperature $T_{1}$. The sample is in good electrical and thermal contact with a heat sink and also is connected to a thermocouple measuring $\mathrm{T}_{0}$.

A second thermocouple $(\mathrm{Cu}-\mathrm{Cu})$ positioned on the sample, located far from the heated probe and is placed on an ice-column, which acts as a "heat sink". The sample is in good electrical and thermal contact with a heat sink and second thermocouple measures temperature $T_{0}$. The probe heats the sample in the vicinity of the tip leading to a temperature gradient and the voltage difference between the corresponding thermocouple branches is measured.

Thus, the voltages $U_{1}$ and $U_{2}$ are measured between the corresponding thermocouples branches respectively, yielding the Seebeck coefficient $\alpha_{\mathrm{S}}$ according to the equations:

$$
\begin{aligned}
& U_{1}=\left(\alpha_{S}-\alpha_{C u}\right) \cdot\left(T_{1}-T_{0}\right) \\
& U_{2}=\left(\alpha_{S}-\alpha_{\mathrm{CuNi}}\right) \cdot\left(T_{1}-T_{0}\right) .
\end{aligned}
$$


Combining Eqs. (1) and (2) we get

$$
\alpha_{s}=\frac{U_{1}}{U_{2}-U_{1}}\left(\alpha_{C u}-\alpha_{C u N i}\right)+\alpha_{C u}
$$

which is the Seebeck coefficient of the sample at the position of the probe tip [44].

The thermocouples that were used in the Seebeck coefficient measurement set-up were purchased from tc Direct ltd [45]. They are made from fine wires of copper and copperconstantan, the Seebeck coefficients of which are known to a high degree of accuracy and measuring temperatures with high degree of accuracies of about $0.5 \mathrm{~K}$ [45].

Since the temperature gradient across the sample $\mathrm{T} 1$ (hot) $\mathrm{T}(0)$ cold $=15 \mathrm{~K}$ in our case , this leads to an accuracy of measurements to be within $5 \%$ when using a polycrystalline bismuth foil reference standard. The whole system was calibrated using copper-constantan thermocouples and a high precision Keithley DMM 2000/E digital multimeter with $0.1 \%$ accuracy. To ensure that the measured temperature is the exact surface temperature, appropriate levels of pressures were applied to ensure good thermal contact between the sample and thermocouples tips.

To characterize the transport properties of the films, values of Hall coefficient $R_{H}(\mathrm{~cm} / \mathrm{C})$, electrical resistivity, $\rho(\Omega \mathrm{cm})$, mobility, $\mu_{\mathrm{e} / \mathrm{n}-\mathrm{p}}\left(\mathrm{cm}^{2} / \mathrm{Vs}\right)$ and carrier concentration, $\mathrm{n} / \mathrm{p}\left(\mathrm{cm}^{-3}\right)$, were measured using a HMS 300 Hall effect measurement unit from Ecopia.

Fig. 2: a) Operational principle of the Seebeck coefficient measurements; b) Picture of custom-made measurement unit

\section{Results and Discussion}

\subsection{Microstructural results for novel nanotemplates and nanomaterials}

Figure 3 shows scanning electron microscopy (SEM) images of the resulting pores, which were produced by wet chemical etching of the ion-track irradiated polyimide films. The pore diameter varied between $30 \mathrm{~nm}$ and $120 \mathrm{~nm}$ for different areas of the polyimide samples. Then, a $200 \mathrm{~nm}$ of gold seed layer was evaporated for the subsequent electroplating process. 
Fig. 3: SEM images of polyimide, $5 \times 10^{9}$ ions $/ \mathrm{cm}^{2}$ (Kapton $H N, \sim 20 \mu m$ thick), ion-track etched, 40 min in $\mathrm{H}_{2} \mathrm{O}_{2}\left(60^{\circ} \mathrm{C}\right)$ followed by a) $5 \mathrm{~min}$ and b) 7 min in $\mathrm{NaOCl}\left(60^{\circ} \mathrm{C}\right)$. The pores have diameters from 30 to $120 \mathrm{~nm}$.

Since the aim of this work was to develop a nanostructured TE device onto a flexible substrate, which is very difficult to fabricate using existing standard MEMS processes, a combination of ion-track nanolithography with electroplating has been shown to be a very elegant alternative manufacturing solution. Ion-track nanolithography templates for electroplating with thick polymers, resulting in high pore densities $\left(10^{9-10} / \mathrm{cm}^{2}\right)$ of submicron size, are compatible with microfabrication technologies and result in very high-aspect ratio nanostructures $(1: 1000)[28]$.

Simultaneously, optimised electroplating parameters were established for submicron $\mathrm{Bi}_{2} \mathrm{Te}_{3}$ and $\mathrm{Bi}_{0.5} \mathrm{Sb}_{1.5} \mathrm{Te}_{3}$ nanowires fabrication. Figure 4 shows $\mathrm{Bi}_{2} \mathrm{Te}_{3}$ nanowires electroplated into polyimide nanostructured templates. Although the pore diameters varied from 30 to $120 \mathrm{~nm}$, the average diameter of the electroplated nanowires was about 80-120 nm (Figure 4) due to capillary forces, which prevented penetration of plating solution into smaller areas. Some regions of samples showed an overgrowth (mushroom-type structure) due to different pore size, which induced a different electrodeposition rate across the whole area.

a)

Fig.4: a) SEM image of a cross section of $\mathrm{Bi}_{2} \mathrm{Te}_{3}$ nanowires deposited at $-0.2 \mathrm{~V}$ vs. SCE at room temperature into polyimide template; b) $B i_{2} T e_{3}$ nanowires overgrowth structure

The electrodeposition rate is controlled by the Faraday law, expressed as the following:

$\mathrm{Q}=\mathrm{I} \cdot \mathrm{t}=\frac{n F W}{M}$

where Q- quantity of electric charge passed through an electrochemical cell, Coulombs; I- 
current, A; t- time, s; n- number of electrons involved in electrodeposition process; F- Faraday constant 96,485 $\mathrm{C} \mathrm{mol}^{-1}$; W-weight of deposited material, g; M -atomic weight of deposited material.

The electroplating duration is controlled by the current, and the same amount of current is applied across the whole sample area. However, the pores' size is different, hence the rate of filling these pores across the whole surface area is different.

From the SEM images it is not conclusive what the relationship between the bigger pore size and a preferential overgrowth in them is.

Since the same amount of charge/current is simultaneously applied to both bigger and smaller pores (with an average pore diameter of $80 \mathrm{~nm}$ ), than in principle, the smaller pores would be filled quicker and overgrowth occurs faster in these.

This can be explained from the following modified Faradays equation, which includes the plated surface area:

$t=\frac{h \cdot a \cdot d}{Z I}$

where h-height of the plated structure, $\mathrm{cm}$; a-surface area, $\mathrm{cm}^{2} ; \mathrm{Z}$ is the electrochemical equivalent, the constant of proportionality; I-current, A; t-time required to deposit material, s [46].

Then, in electrodeposition of nanostructures, there is a minimum pore size of around 50nm and below where diffusion mechanisms are limited which leads to a significant slower electrodeposition rate to fill in such pores. However, this is not applicable to our case, as the average pores size was $80 \mathrm{~nm}$, which means that diffusion will not be limited and will not affect the electrodeposition rate. Hence, in our case, it is expected that smaller size pores would be filled up first.

The overgrowth structure (shown in Fig.3) reveals the surface morphology of the electroplated nanostructures and is consistent with this of an electroplated film of the same 
composition (i.e. Bi2Te3). The grain size in this region varies between $\sim 100 \mathrm{~nm}$ up to $\sim 2$ microns. The information about the grain sizes of electrodeposited structures is important as it contributes to an optimisation of material's thermoelectric properties (electrical and thermal conductivities).

After dissolving for $5 \mathrm{~min}$ the nanowires were thoroughly liberated from the foils (Fig. 5). However, NMP/MEA compositions (wt \%) of 90/10 were found to be too aggressive, because nanowires were partially destroyed (Fig. 5a). Indeed, as can be seen from Figure 5a, the liberated nanowire length was about $6.9 \mu \mathrm{m}$, only about a third of the length of the $20 \mu \mathrm{m}$ long nanowires held in the polyimide template. For the NMP/MEA ratio of 30/70(wt \%), the entire length of electrodeposited nanowires $(\sim 20 \mu \mathrm{m})$ was preserved. Thus, this ratio was found to be an optimum mixture for dissolving the polyimide template.

a)

b)

Fig.5: SEM images of $B i_{0.5} S b_{1.5} T_{3}$ nanowires liberated from Kapton foil by dissolving in NMP (N-methylpyrrolidone)/MEA (monoethanol-amine) (a) NMP/MEA compositions (wt \%) of 90/10, resulting in 6.9 um long nanowires; (b) NMP/MEA compositions (wt \%) of 30/70 resulting in $20 \mu \mathrm{m}$ long nanowires.

In addition, our investigations on electrochemically deposited $\mathrm{Bi}_{2-\mathrm{x}} \mathrm{Sb}_{\mathrm{x}} \mathrm{Te}_{3}$ nanostructures reveal that the crystallinity and texture can be controlled by the deposition parameters. Scanning electron microscopy (SEM) associated with energy-dispersive spectrometry and Xray diffraction, evidenced a microcrystalline structure with a single phase of $\mathrm{Bi}_{2} \mathrm{Te}_{3}$ and $\mathrm{Bi}_{0.5} \mathrm{Sb}_{1.5} \mathrm{Te}_{3}$ with a preferential crystalline orientation in (110) planes for both compounds, which is a preferred texture for maximizing the thermoelectric properties of $\mathrm{Bi}_{2-\mathrm{x}} \mathrm{Sb}_{\mathrm{x}} \mathrm{Te}_{3}$ alloys (Figure 6). 
$\mathrm{Bi}_{0.5} \mathrm{Sb}_{1.5} \mathrm{Te}_{3}$ crystals with space group $\mathrm{R}^{-} 3 \mathrm{~m}$ except for the peaks of $\mathrm{Au}$, which come from the gold seed layer that was used as a working electrode. Therefore, polycrystalline single phase $\mathrm{Bi}_{2} \mathrm{Te}_{3}$ and $\mathrm{Bi}_{0.5} \mathrm{Sb}_{1.5} \mathrm{Te}_{3}$ compounds were successfully electroplated. According to XRD observations, the electroplated nanowires appear to have a preferential crystalline orientation in (110) planes.

Fig. 6: XRD of a) $\mathrm{Bi}_{2} \mathrm{Te}_{3}$ and b) $B i_{0.5} \mathrm{Sb}_{1.5} \mathrm{Te}_{3}$ nanowire composition by electroplating

The HIM image in figure 6 reveals that the nanowires exhibit a hexagonal crystallographic structure. In addition to an important confirmation and revelation that the nanowires exhibit a hexagonal crystallographic structure, which is consistent with the crystallographic structure of these materials in other forms (e.g. thin films, single crystal), it can be seen that they charged up under the ion beam, indicating their low electrical conductivity. We had to use an electron flood gun to neutralise the surface charge in order to capture this clear image. Hence, this conclusion suggests that further nanowires optimisations might be needed in order to increase electrical conductivity, which is one of desired parameters for materials for thermoelectric applications.

Fig. 7: Helium microscope image of $\mathrm{Bi}_{0.5} \mathrm{Sb}_{1.5} \mathrm{Te}_{3}$ nanowires with hexagonal crystallographic structure

The chemical composition of $\mathrm{Bi}_{2} \mathrm{Te}_{3}$ films and nanowires by EDS gave a constant Te content of $\sim 59.05$ at $\%$, and a Bi content of 40.95 at $\%$. As far as $\mathrm{Bi}_{0.5} \mathrm{Sb}_{1.5} \mathrm{Te}_{3}$ is concerned, EDS resulted in 12 at $\%, 30$ at $\%$ and 58 at $\%$ of $\mathrm{Bi}, \mathrm{Sb}$ and Te contents respectively. Thus, according to the EDS technique, both types of alloys were nearly stoichiometric. Deviations in chemical composition, however, have been observed by microprobe analyses which revealed an excess of $\mathrm{Bi}$ for the binary $\mathrm{Bi}_{2} \mathrm{Te}_{3}$ alloy and a deficit in $\mathrm{Bi}$ and $\mathrm{Sb}$ for the ternary $\mathrm{Bi}_{0.5} \mathrm{Sb}_{1.5} \mathrm{Te}_{3}$ alloy (table 1). These deviations from the nominal composition match previous observations $[1,47$, 
48]. According to Horak et al. this can be explained by native defects (antisite type) in the structures of $\mathrm{Bi}_{2} \mathrm{Te}_{3}, \mathrm{Sb}_{2} \mathrm{Te}_{3}$ and its solid solutions $\left(\mathrm{Bi}_{2-\mathrm{x}} \mathrm{Sb}_{\mathrm{x}} \mathrm{Te}_{3}\right)$. In the crystal lattice, excess $\mathrm{Bi}$ atoms take the place of the $\mathrm{Te}^{\mathrm{II}}$ sites and thus there is the formation of antisite Bi'Te defects. Miller et al. showed experimentally that defects of antisite type predominate in samples with excess of Bi [49]. Previous density measurements by Przyluski et al.[50] and more recent heterodiffusion studies by Drabble et al. [51] showed that defects of antisite type should predominate in samples with an excess of $\mathrm{Bi}$ [1]. This type of $\mathrm{Bi}_{2} \mathrm{Te}_{3}$ compound is considered quasi-stoichiometric [35].

In order to reach a stoichiometric chemical composition, thermal treatment of the films was used to anneal native structural defects and to improve their thermoelectric performance. Consequently, $\mathrm{Bi}_{0.5} \mathrm{Sb}_{1.5} \mathrm{Te}_{3}$ alloy was thermally treated at $260{ }^{\circ} \mathrm{C}$ for $30 \mathrm{~min}$, which resulted in a very homogeneous distribution of $\mathrm{Bi}, \mathrm{Sb}$ and $\mathrm{Te}$ (at \%) across the samples, with variations of less than $3 \%$, an acceptable value. Due to diffusion processes, heat treatment leads to the defects' annihilation, in particular, antisite defects, which induce a variation of chemical composition. However, deviations from stoichiometry for $\mathrm{Bi}_{0.5} \mathrm{Sb}_{1.5} \mathrm{Te}_{3}$ remained significant after heat treatment. Consequently, $\mathrm{Bi}_{0.5} \mathrm{Sb}_{1.5} \mathrm{Te}_{3}$, which is known to be an effective material for thermoelectric generation, probably has more complex defect mechanisms, which can include not only antisite defects but also dislocations. However, the studies by Eyidi et al. showed that defect structures in $\mathrm{Bi}_{2} \mathrm{Te}_{3}$ extend down to between 2 and $20 \mu \mathrm{m}$ in depth [52]. This suggests that a small deviation from stoichiometric composition can be typically observed in the superficial layer of this material, and this may vary from one type of thin film fabrication technique to another. In fact, non-homogeneity of the evolution of the chemical composition through the sample thickness has been observed previously [53, 54]. Therefore, further analysis of the variation of chemical composition with depth is necessary. 
In addition, the homogeneity of the chemical compositions, which is an important parameter for the performance of thermoelectric materials in raw $\mathrm{Bi}_{2} \mathrm{Te}_{3}$ and $\mathrm{Bi}_{0.5} \mathrm{Sb}_{1.5} \mathrm{Te}_{3}$, across the electroplated surface was determined (figure 8). While the variations in concentration of $\mathrm{Bi}$ (at \%) and $\mathrm{Te}\left(\right.$ at $\%$ ) across $\mathrm{Bi}_{2} \mathrm{Te}_{3}$ samples are small (in the range of $3 \%$ ), these variations are quite significant across the $\mathrm{Bi}_{0.5} \mathrm{Sb}_{1.5} \mathrm{Te}_{3}$ films resulting in $18 \%$ and $22 \%$ for $\mathrm{Sb}$ and $\mathrm{Te}$ (at $\%$ ), respectively. Since, it has been demonstrated that $\mathrm{Bi}_{2-\mathrm{x}} \mathrm{Sb}_{\mathrm{x}} \mathrm{Te}_{3}$ thermoelectric efficiency is related to the control of solid solution composition and stoichiometric deviations [55], an optimization of $\mathrm{Bi}_{0.5} \mathrm{Sb}_{1.5} \mathrm{Te}_{3}$ chemical composition by electrodeposition process is required. However, both the deviation in stoichiometry and variations in concentration can be improved by the annealing of the native structural defects. Consequently, the $\mathrm{Bi}_{0.5} \mathrm{Sb}_{1.5} \mathrm{Te}_{3}$ alloy was thermally treated at $260 \mu \mathrm{C}$ for $30 \mathrm{~min}$ and the homogeneity of the chemical compositions across the samples showed a decrease to $3 \%$ in $\mathrm{Bi}, \mathrm{Sb}$ and $\mathrm{Te}$ (at \%) variations, which is an acceptable value for $\mathrm{Bi}_{2-\mathrm{x}} \mathrm{Sb}_{\mathrm{x}} \mathrm{Te}_{3}$ compounds $[56,50]$. This temperature has been chosen from an evolution of the Seebeck coefficient during annealing which occurred in the interval from 240 to $260^{\circ} \mathrm{C}$.

Thus, new microprobe profiles show that thermal treatment has significantly improved the homogeneneity in the distribution of the elements across the surface for the $\mathrm{Bi}_{0.5} \mathrm{Sb}_{1.5} \mathrm{Te}_{3}$ alloys (figure 8). However, it is evident that the annealed compound has equally exhibited a deficit in $\mathrm{Bi}$ and $\mathrm{Sb}$ and an excess in Te (table 1), which suggests that the electrodeposition process and thermal treatment conditions need further optimization.

Table 1: Chemical composition of $\mathrm{Bi}_{2} \mathrm{Te}_{3}$ and $\mathrm{Bi}_{0.5} \mathrm{Sb}_{1.5} \mathrm{Te}_{3}$ electroplated films surfaces by Microprobe 
These chemical composition results show that for binary $\mathrm{Bi}_{2} \mathrm{Te}_{3}$ and ternary $\mathrm{Bi}_{0.5} \mathrm{Sb}_{1.5} \mathrm{Te}_{3}$ alloys, the electroplating technique can be used to reach stoichiometry and achieve a homogeneous distribution of the elements across the surface.

Fig. 8: Microprobe profiles of a) $B i_{0.5} S_{1.5} \mathrm{Te}_{3}$ not annealed; b) $B i_{0.5} \mathrm{Sb}_{1.5} \mathrm{Te}_{3}$ annealed electroplated films surfaces.

\subsection{Thermoelectric properties performance and thermoelectric energy harvester testing}

The Seebeck coefficient profile was measured along the surface of various raw electroplated $\mathrm{Bi}_{2} \mathrm{Te}_{3}$ and $\mathrm{Bi}_{0.5} \mathrm{Sb}_{1.5} \mathrm{Te}_{3}$ films and the profiles are presented in figures 9 and 10 . Different symbols in the profiles in figures 9 and 10 represent different samples with the same chemical composition. In Fig. 9, samples 1-4 correspond to the $1^{\text {st }}$ batch of the specimen $\mathrm{Bi}_{0.5} \mathrm{Sb}_{1.5} \mathrm{Te}_{3}$ fabricated by electrodeposition while samples 5-8 were obtained from the $2^{\text {nd }}$ batch. In Fig.10, profiles for the samples 1-3 correspond to $\mathrm{Bi}_{2} \mathrm{Te}_{3}$ obtained from a single electrodeposition batch. Each point on these graphs correspond to an average of a minimum of 3 measurements taken at each area. These profiles evidence the uniformity of the Seebeck coefficient across the surface of the $\mathrm{Bi}_{2} \mathrm{Te}_{3}$ and $\mathrm{Bi}_{0.5} \mathrm{Sb}_{1.5} \mathrm{Te}_{3}$ samples. Seebeck coefficients of $\mathrm{Bi}_{2} \mathrm{Te}_{3}$ films are negative and those of the $\mathrm{Bi}_{0.5} \mathrm{Sb}_{1.5} \mathrm{Te}_{3}$ samples are positive, which is indicative of $\mathrm{n}$ - and $\mathrm{p}$-type conductivity, respectively. The maximum values of Seebeck coefficients were $-52 \mu \mathrm{V} / \mathrm{K}$ and $120 \mu \mathrm{V} / \mathrm{K}$ for raw $\mathrm{Bi}_{2} \mathrm{Te}_{3}$ and $\mathrm{Bi}_{0.5} \mathrm{Sb}_{1.5} \mathrm{Te}_{3}$ electroplated films, respectively. Deviation from stoichiometric composition can be one of the reasons that $\mathrm{Bi}_{0.5} \mathrm{Sb}_{1.5} \mathrm{Te}_{3}$ Seebeck coefficients were below the maximum values previously achieved by electrodeposition [57].

Fig. 9: Seebeck coefficient profiles across the area of the $B i_{0.5} S b_{1.5} T_{e_{3}}$ electroplated films (Samples 1-8 have the same chemical composition of $\mathrm{Bi}_{0.5} \mathrm{Sb}_{1.5} \mathrm{Te}_{3}$. Any differences in Seebeck coefficient values are due to variations in electroplating processing). 
Fig. 10: Seebeck effect profiles across the area of the Bi $i_{2} \mathrm{Te}_{3}$ electroplated films (Samples 1-3 have the same chemical composition of $B i_{2} \mathrm{Te}_{3}$. Any differences in Seebeck coefficient values are due to variations in electroplating processing).

Table 2: Transport properties for $\mathrm{Bi}_{2} \mathrm{Te}_{3}$ and $\mathrm{Bi}_{0.5} \mathrm{Sb}_{1.5} \mathrm{Te}_{3}$ films

The influence of annealing on the thermoelectric properties of the deposited material was also evaluated since the thermoelectric properties can be improved by eliminating various defects in the crystalline structure, which typically occur in $\mathrm{Bi}_{2-\mathrm{x}} \mathrm{Sb}_{\mathrm{x}} \mathrm{Te}_{3}$ compounds [58]. The electrodeposited samples having a thickness of about $12-16 \mu \mathrm{m}$ were annealed for 30 minutes at temperatures ranging from 240 to $260{ }^{\circ} \mathrm{C}$. The Seebeck coefficient of the annealed alloys was then measured and showed an increase from -51 to $-60 \mathrm{mV} / \mathrm{K}$ for $\mathrm{Bi}_{2} \mathrm{Te}_{3}$ and from 120 to $\sim 180 \mu \mathrm{m} / \mathrm{V}$ for $\mathrm{Bi}_{0.5} \mathrm{Sb}_{1.5} \mathrm{Te}_{3}$ electroplated films. Table 3 includes the Seebeck coefficient measured and compared with these of bulk values.

\begin{tabular}{|c|c|c|c|}
\hline $\begin{array}{l}\text { Seebeck coefficient } \\
\text { measured in this } \\
\text { manuscript for } \\
\text { raw/annealed } \mathrm{Bi}_{2} \mathrm{Te}_{3} \text {, } \\
\mu \mathrm{V} / \mathrm{K}\end{array}$ & $\begin{array}{l}\text { Examples of Seebeck } \\
\text { coefficient values for } \\
\text { bulk } \mathrm{Bi}_{2} \mathrm{Te}_{3}, \mu \mathrm{V} / \mathrm{K}\end{array}$ & $\begin{array}{l}\text { Seebeck coefficient } \\
\text { measured in this } \\
\text { manuscript for } \\
\text { raw/annealed } \\
\mathrm{Bi}_{0.5} \mathrm{Sb}_{1.5} \mathrm{Te}_{3,} \mu \mathrm{V} / \mathrm{K}\end{array}$ & $\begin{array}{l}\text { Examples of } \\
\text { Seebeck coefficient } \\
\text { values for bulk } \\
\mathrm{Bi}_{0.5} \mathrm{Sb}_{1.5} \mathrm{Te}_{3,}, \mu \mathrm{V} / \mathrm{K}\end{array}$ \\
\hline $\begin{array}{l}-52 \text { for raw films } \\
-60 \text { for annealed films }\end{array}$ & $\begin{array}{l}-231[59] \\
-210[60] \\
-170-220[61] \\
-225[1]\end{array}$ & $\begin{array}{l}120 \text { for raw films } \\
\sim 180 \text { for annealed } \\
\text { films }\end{array}$ & $\begin{array}{l}180-190[60,1] \\
132-180[59]\end{array}$ \\
\hline
\end{tabular}

Table 3: Seebeck coefficient for $\mathrm{Bi}_{2} \mathrm{Te}_{3}$ and $\mathrm{Bi}_{0.5} \mathrm{Sb}_{1.5} \mathrm{Te}_{3}$ films compared with the values for bulk materials

From these comparisons of Seebeck coefficients values above, it appears that whilst the values for Seebeck coefficient of $\mathrm{Bi}_{0.5} \mathrm{Sb}_{1.5} \mathrm{Te}_{3}$ electroplated films are comparable with those values for bulk materials, Seebeck coefficients of $\mathrm{Bi}_{2} \mathrm{Te}_{3}$ electroplated films are lower. As far as the comparison of Seebeck coefficients for electroplated $\mathrm{Bi}_{2} \mathrm{Te}_{3}$ and $\mathrm{Bi}_{0.5} \mathrm{Sb}_{1.5} \mathrm{Te}_{3}$ films is concerned, whilst these values for $\mathrm{Bi}_{2} \mathrm{Te}_{3}$ are comparable to the ones existing in the literature [59], Seebeck coefficient for $\mathrm{Bi}_{0.5} \mathrm{Sb}_{1.5} \mathrm{Te}_{3}$ are higher in the present work [60]. 
Transport properties have been simultaneously evaluated. However, due to the fragile nature of these compounds, methods of samples preparation require optimization as various microcracks appeared while preparing ohmic contacts. As far as thermoelectric performance is concerned, while the Seebeck coefficient has been improved by $\sim 50 \%$ for annealed alloys, transport properties measurements are yet to be optimised. High electrical resistivity and very low mobility (from 18 to 35 and from 1.4 to $22 \mathrm{~cm}^{2} / \mathrm{Vs}$ respectively) were observed for $\mathrm{Bi}_{2} \mathrm{Te}_{3}$ and $\mathrm{Bi}_{0.5} \mathrm{Sb}_{1.5} \mathrm{Te}_{3}$ annealed films (see table 2), which could be due to mechanical damage of the nanostructures while preparing samples for measurements.

Finally, a novel thermoelectric generator (figure 11) was tested by applying thermal gradients across the substrate and measuring the resulting voltage generated.

A schematic of the layout of the mask that was used to fabricate this device (as described earlier in the section 2.1 Microfabrication process) shows 16 thermocouples connected in series. Whilst the oveall size of the prototype is $29 \mathrm{mmx} 47 \mathrm{~mm}$, areas taken by each individual thermocouple where $n$ - and p-types of nanowires were electroplated are $4.5 \mathrm{mmx} 5.5 \mathrm{~mm}$. Mask design was realised by using a professional design software L-Edit.

This device was mounted on an aluminium block having a heat sink (340 heat sink compound from Dow Corning), which was then placed onto an iced surface. The temperature gradient, which was created between the ambient and cold side, resulted in a temperature difference of only $\sim 13{ }^{\circ} \mathrm{C}$, measured by a commercial type $\mathrm{T}$ thermocouple thermometer BAT-10 from Physitemp Instruments Inc. The voltage output from this device was observed on an oscilloscope, DS03062A. Thus, a novel TE generator was fabricated onto a flexible substrate, which consisted of nanowired thermoelectric elements with significantly higher aspect ratio $(1: 250)$ and density $\left(5 \times 10^{9}\right.$ wires $\left./ \mathrm{cm}^{2}\right)$ than existing ones which have been produced both commercially and also in various research laboratories. This structure provides 
increasing performance efficiency through enhanced charge carrier mobility by quantum confinement effects and by increased phonon scattering. In fact, while a typical value of the voltage from commercial TE generators is around $2.8 \mathrm{~V}$ from a $\sim 3500 \mathrm{~mm}^{3}$ device requiring a temperature difference of $50-70{ }^{\circ} \mathrm{C}[2]$, the generator described here produced $0.6 \mathrm{~V}$ in the open circuit from a significant smaller functional area $\left(\sim 16 \mathrm{~mm}^{3}\right)$ and temperature difference (below $20 \mathrm{~K}$ ).

Fig. 11: a) Photograph of a nanostructured TE prototype device onto a polyimide flexible substrate; b) high density $5 \times 10^{9} \mathrm{Bi}_{0.5} \mathrm{Sb}_{1.5} \mathrm{Te}_{3}$ nanowires $/ \mathrm{cm}^{2}$ released from nanotemplate for microstructural characterization; c) schematic of the layout of the mask design for a nanostructured TE prototype

\section{Conclusion}

We have demonstrated that a combination of ion-track nanolithography and electroplating is a promising technique for the realisation of nanostructured thermoelectric generators on flexible substrates. These devices are suitable for wearable applications as they can conform to the various contours of the geometry geometry upon which it is mounted. Polyimide (Kapton foil, $20 \mu \mathrm{m}$ ) was shown to be a promising material for the fabrication of ion-track nanostructured templates which have been successfully used to form electroplated $\mathrm{Bi}_{2} \mathrm{Te}_{3}$ and $\mathrm{Bi}_{0.5} \mathrm{Sb}_{1.5} \mathrm{Te}_{3}$ nanowires as $\mathrm{n}$ - and p-types elements. This polymer is compatible with standard silicon microfabrication batch processes, which provides an elegant solution for MEMS type TE generators using low-cost batch manufacturing.

The novel technological route developed here was found to be a promising approach for realising nanostructured energy harvesters on flexible substrates operating at temperature gradients below $20^{\circ} \mathrm{C}$ and suitable for wearable applications. By comparison, current commercial TE generators operate at temperature gradient of $50-70{ }^{\circ} \mathrm{C}$ and are fabricated on rigid substrates. 
In addition, significant progress in nanotechnologies and materials science was achieved. Polyimide nanotemplates with $30-120 \mathrm{~nm}$ pore diameters and high aspect ratios (1:1000) were produced, and used for the growth of high-aspect-ratio $\mathrm{Bi}_{2} \mathrm{Te}_{3}$ and $\mathrm{Bi}_{0.5} \mathrm{Sb}_{1.5} \mathrm{Te}_{3}$ nanowires (80 and $120 \mathrm{~nm}$ diameter) by an electroplating process. Both electrodeposited compounds have very promising microstructural properties as they are of $\mathrm{R} \overline{3} \mathrm{~m}$ crystallographic structure with the preferential grain orientation in (110), which is an optimal texture for the best thermoelectric performance. However, the chemical composition of the p-type element in BiSb-Te materials needs to be optimised. While $\mathrm{Bi}_{2} \mathrm{Te}_{3}$ films have been deposited with close to stoichiometry composition, $\mathrm{Bi}_{0.5} \mathrm{Sb}_{1.5} \mathrm{Te}_{3}$ samples exhibited significant deviations in chemical composition with a deficit in $\mathrm{Bi}($ at \%) and $\mathrm{Sb}$ (at \%). Therefore, an optimisation of electroplating parameters to decrease deviation from the stoichiometry for $\mathrm{Bi}_{0.5} \mathrm{Sb}_{1.5} \mathrm{Te}_{3}$ is necessary.

In addition, the physical properties performance of electroplated films $\mathrm{Bi}_{2} \mathrm{Te}_{3}$ and $\mathrm{Bi}_{0.5} \mathrm{Sb}_{1.5} \mathrm{Te}_{3}$ needs to be improved further. While Seebeck coefficients of $\mathrm{Bi}_{2} \mathrm{Te}_{3}$ and $\mathrm{Bi}_{0.5} \mathrm{Sb}_{1.5} \mathrm{Te}_{3}$ reached significant improvements of up to 20 and $50 \%$, respectively, using thermal treatment to remove various defects of the microcrystalline structure, transport properties still need to be optimised, as the Hall mobility was low (from 1.4 to $35 \mathrm{~cm}^{2} / \mathrm{Vs}$ ) and carrier concentrations were high $\left(10^{21}\right.$ to $\left.10^{22} \mathrm{~cm}^{-3}\right)$.

Future work will include further optimisations of annealing parameters, measurements of $\mathrm{Bi}_{2} \mathrm{Te}_{3}$ and $\mathrm{Bi}_{0.5} \mathrm{Sb}_{1.5} \mathrm{Te}_{3}$ nanowires thermoelectric and properties and transport properties, further optimisation of device design and the test set-up for a flexible nanostructured generator, which includes detailed flexibility to explore devices mechanical robustness.

\section{Acknowledgments}

Dr J Kuleshova and Dr X. Li from the University of Southampton School of Chemistry and School of Engineering (now at base4Ltd and lecturer at the University of Exeter respectively) 
are acknowledged for their support in performing electrodeposition of $\mathrm{Bi}_{2} \mathrm{Te}_{3}$ and $\mathrm{Bi}_{0.5} \mathrm{Sb}_{1.5} \mathrm{Te}_{3}$. We thank Dr C Trautmann and Dr B Schiedt from GSI (Germany) for the iontrack irradiation and Prof SP Beeby, and Dr M Tudor for useful discussions.

\section{Illustrations}




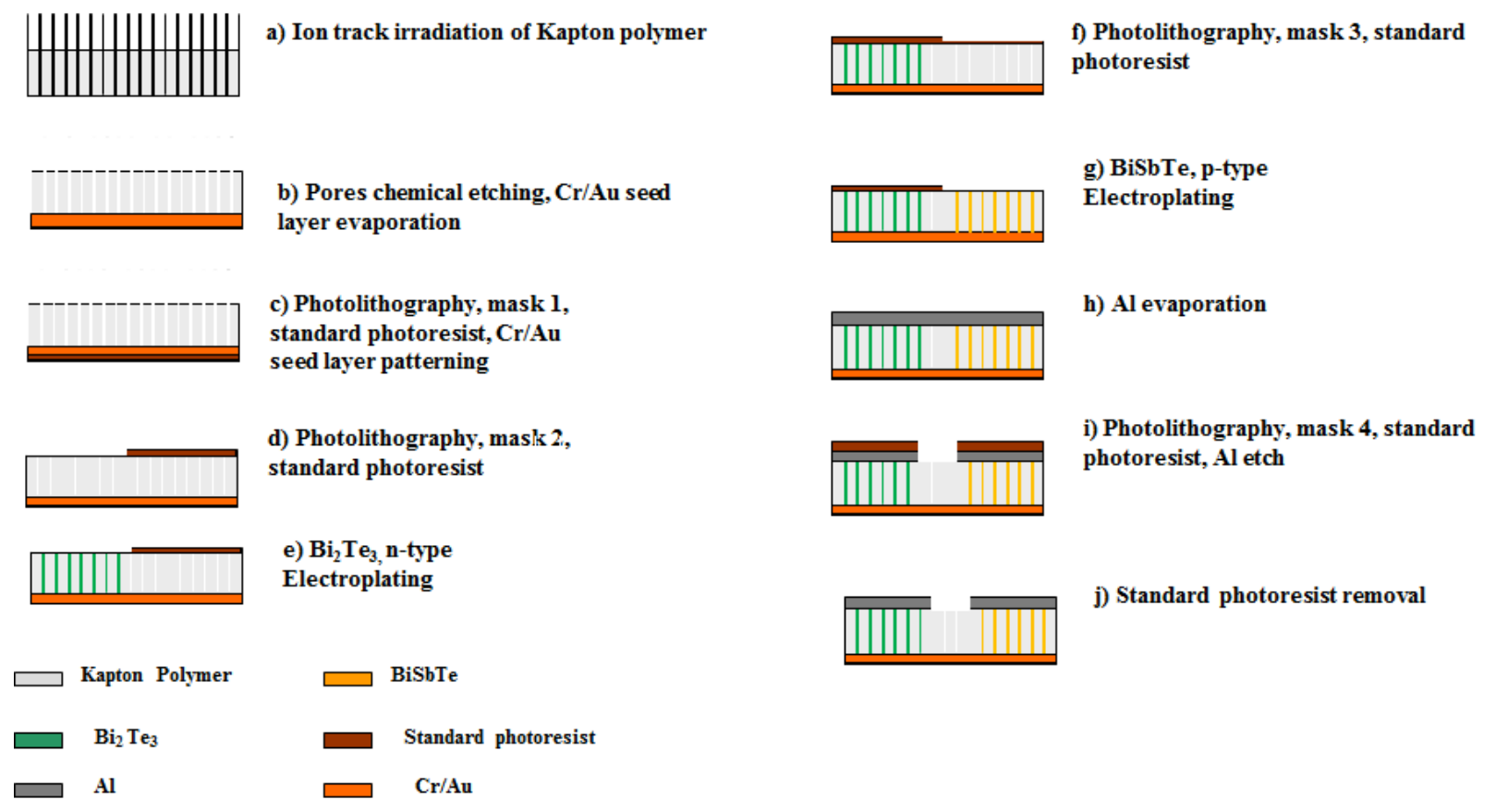

Fig.1: Process flow of a thermoelectric microgenerator on a flexible substrate 


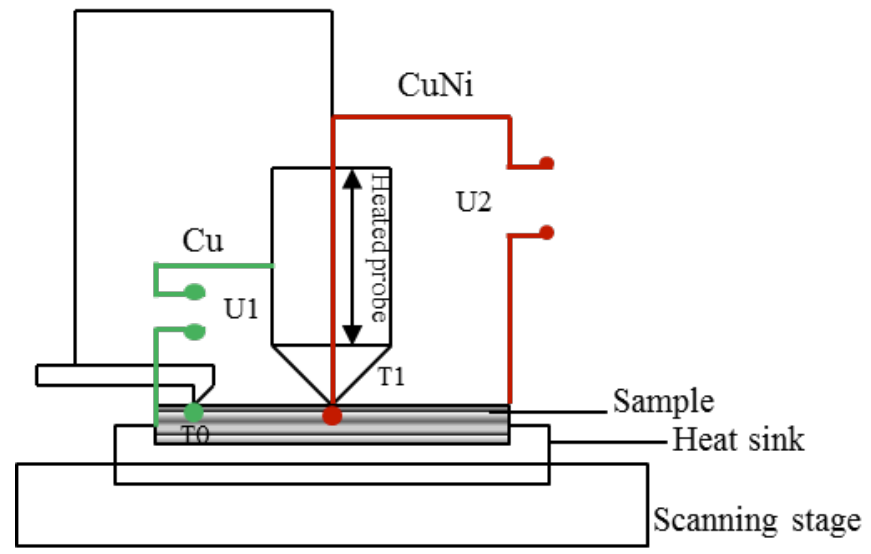

Figure 2a

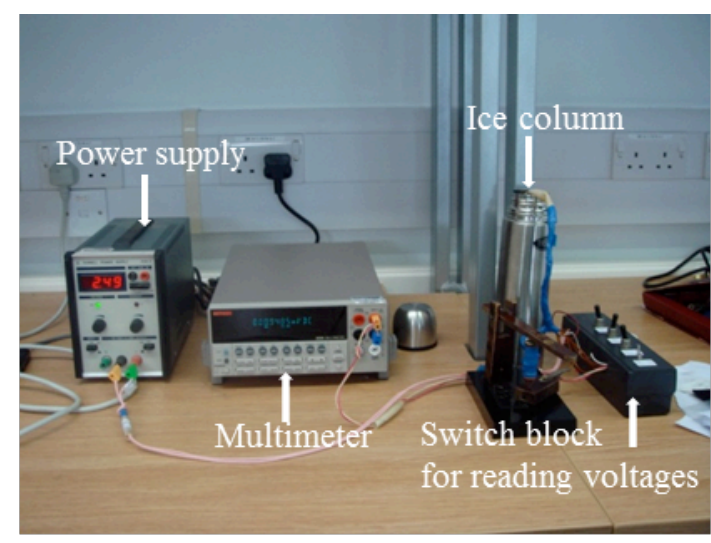

Figure $2 b$

Fig. 2: a) Operational principle of the Seebeck coefficients measurements; b) Picture of custom-made measurement unit

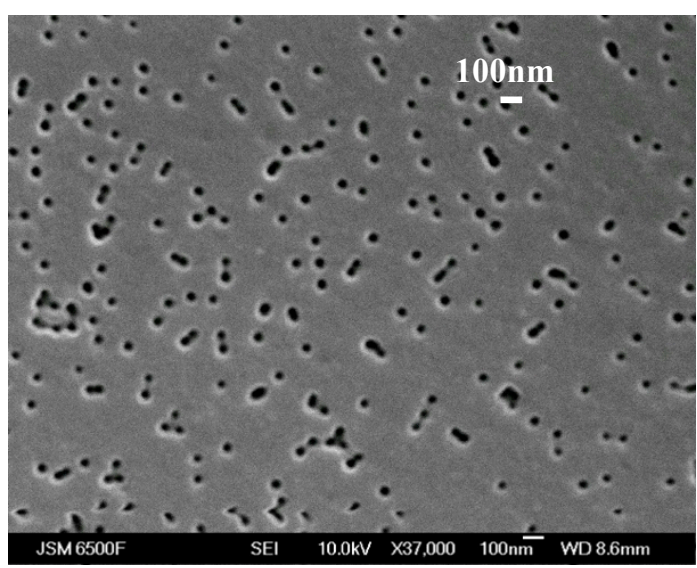

a)

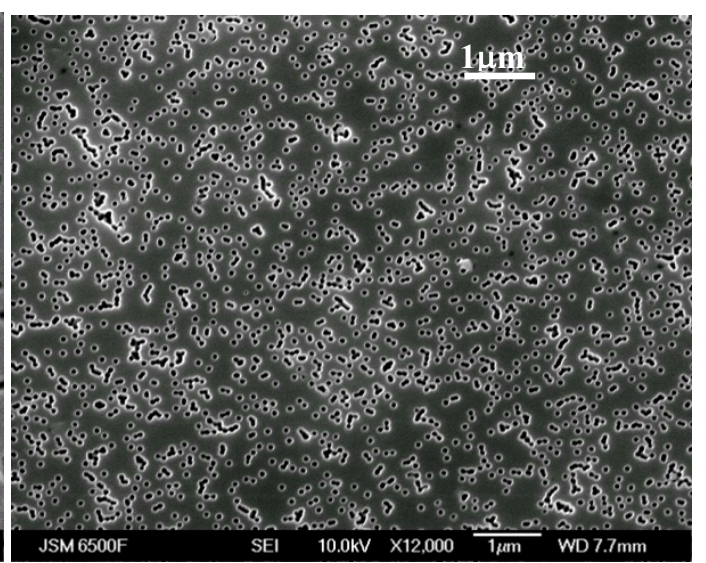

b)

Fig. 3: SEM images of polyimide, $5 \times 10^{9}$ ions $/ \mathrm{cm}^{2}$ (Kapton $\mathrm{HN}, \sim 20 \mu \mathrm{m}$ thick), ion-track etched, 40 min in $\mathrm{H}_{2} \mathrm{O}_{2}\left(60^{\circ} \mathrm{C}\right)$ followed by a) $5 \mathrm{~min}$ and b) $7 \mathrm{~min}$ in $\mathrm{NaOCl}\left(60^{\circ} \mathrm{C}\right)$. The pores have diameters from 30 to $120 \mathrm{~nm}$. 


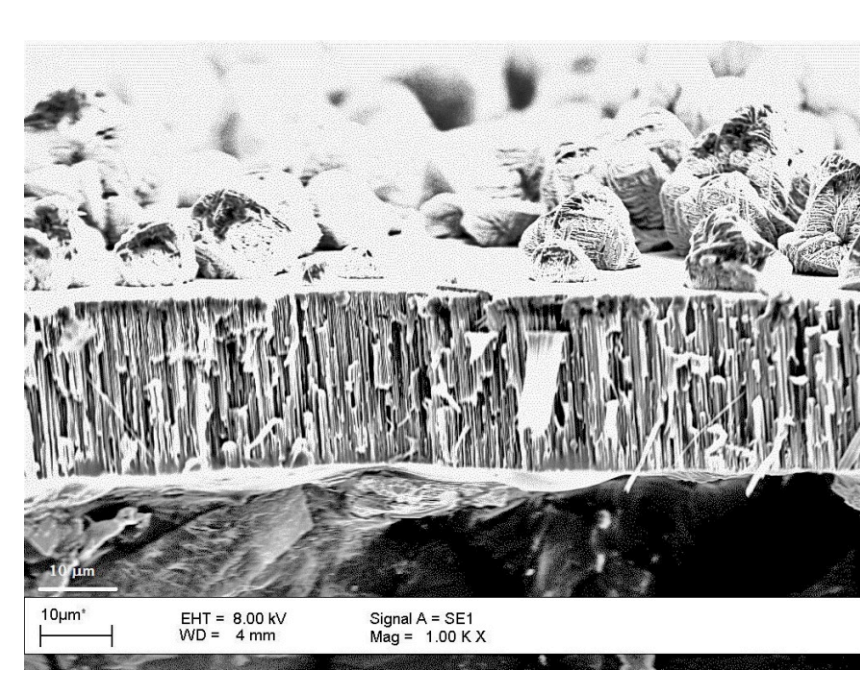

a)

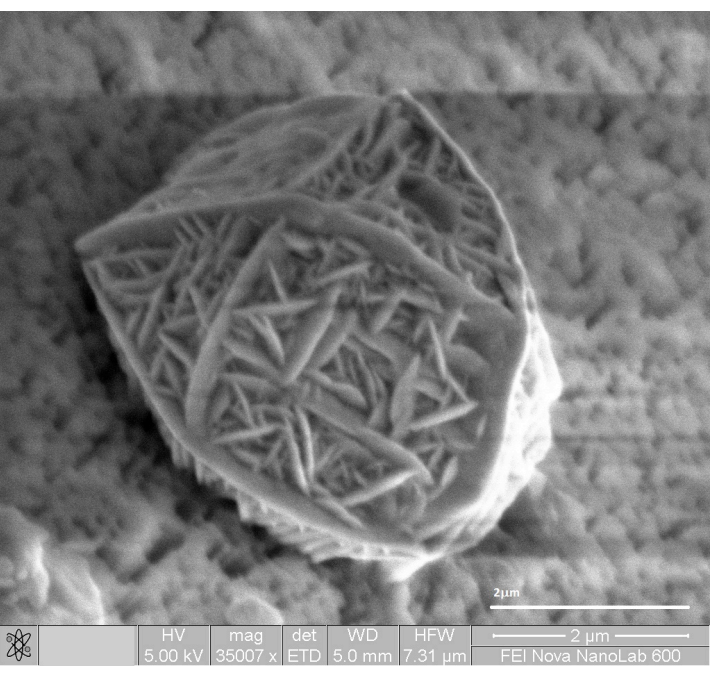

b)

Fig.4: a) SEM image of a cross section of $\mathrm{Bi}_{2} \mathrm{Te}_{3}$ nanowires deposited at $-0.2 \mathrm{~V}$ vs. SCE at room temperature into polyimide template; $b$ ) $\mathrm{Bi}_{2} \mathrm{Te}_{3}$ nanowires overgrowth structure

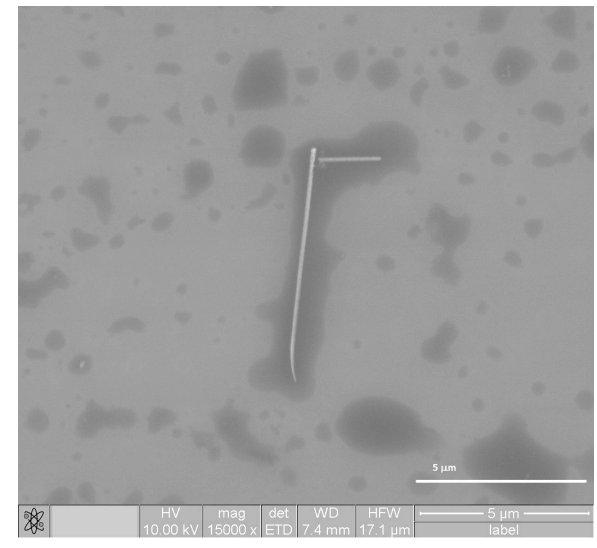

a)

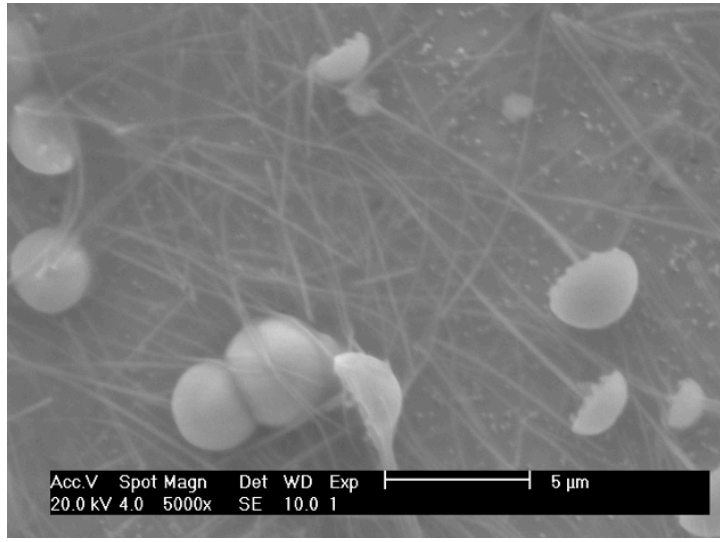

b)

Fig.5: SEM images of $\mathrm{Bi}_{0.5} \mathrm{Sb}_{1.5} \mathrm{Te}_{3}$ nanowires liberated from Kapton foil by dissolving in NMP (N-methylpyrrolidone)/MEA (monoethanol-amine) (a) NMP/MEA compositions (wt $\%$ ) of 90/10, resulting in $6.9 \mu \mathrm{m}$ long nanowires; (b) NMP/MEA compositions (wt \%) of $30 / 70$ resulting in $20 \mu \mathrm{m}$ long nanowires. 

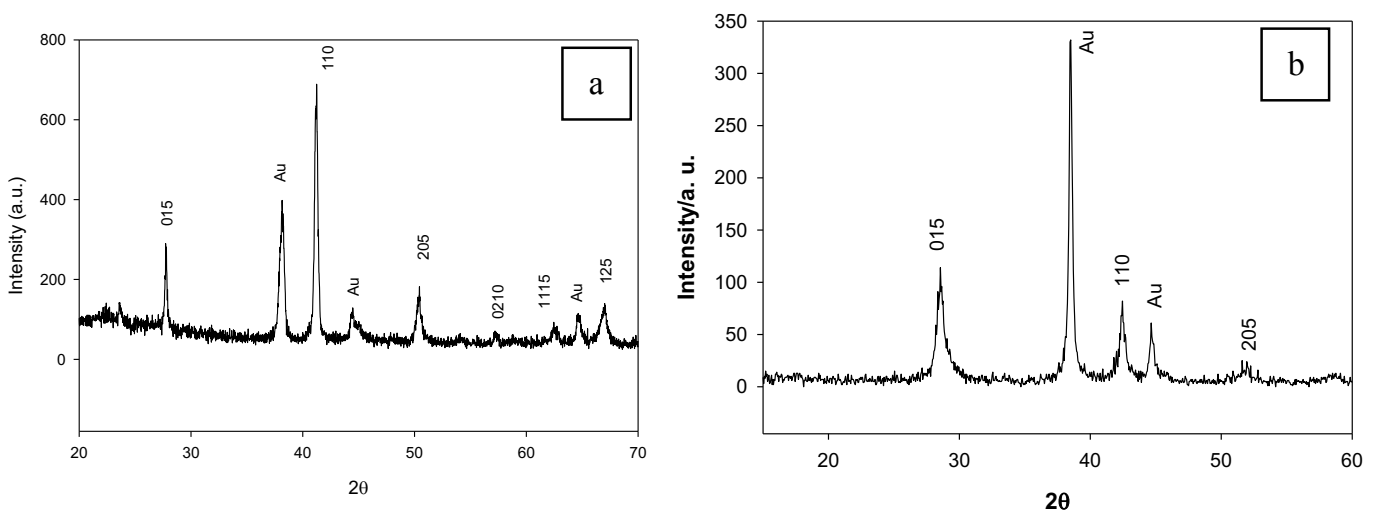

Fig. 6: XRD of a) $\mathrm{Bi}_{2} \mathrm{Te}_{3}$ and b) $\mathrm{Bi}_{0.5} \mathrm{Sb}_{1.5} \mathrm{Te}_{3}$ nanowire composition by electroplating 


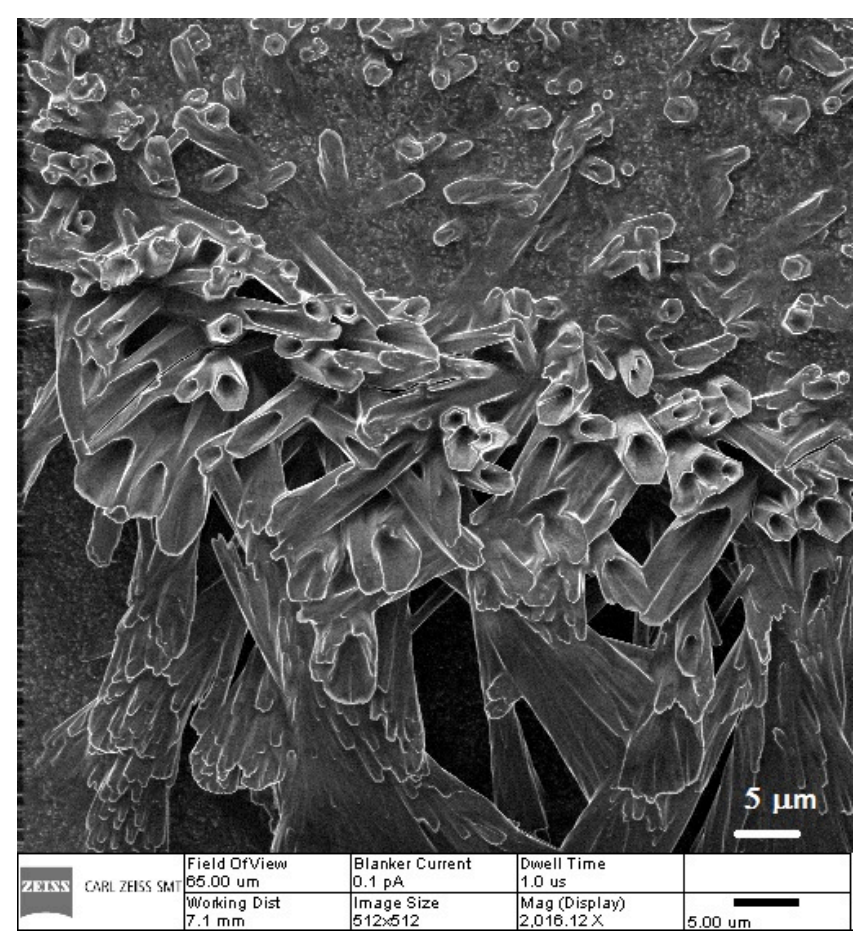

Fig. 7: Helium microscope image of $\mathrm{Bi}_{0.5} \mathrm{Sb}_{1.5} \mathrm{Te}_{3}$ nanowires with hexagonal crystallographic structure

\begin{tabular}{|c|c|c|c|c|}
\hline Theoretical formulation & $\mathrm{Bi}_{2} \mathrm{Te}_{3}$ & \multicolumn{3}{|c|}{$\mathrm{Bi}_{0.5} \mathrm{Sb}_{1.5} \mathrm{Te}_{3}$} \\
\hline Sample ID & Sample1 & Sample2 & $\begin{array}{c}\text { Sample2, } \\
\text { annealed }\end{array}$ \\
\hline Bi concentration (at \%) & 43.37 & 7.39 & 5.95 & 6.5 \\
\hline Sb concentration (at \%) & 0 & 28.88 & 28.63 & 25.58 \\
\hline Te concentration (at \%) & 56.24 & 64.1 & 65.41 & 67.9 \\
\hline Analysed composition & $\mathrm{Bi}_{2.17} \mathrm{Te}_{2.81}$ & $\begin{array}{c}\mathrm{Bi}_{0.37} \mathrm{Sb}_{1 .} \\
{ }_{44} \mathrm{Te}_{3.20}\end{array}$ & $\begin{array}{c}\mathrm{Bi}_{0.29} \mathrm{Sb}_{1 .} \\
{ }_{33} \mathrm{Te}_{3.27}\end{array}$ & $\begin{array}{c}\mathrm{Bi}_{0.32} \mathrm{Sb}_{1 .} \\
{ }_{28} \mathrm{Te}_{3.39}\end{array}$ \\
\hline
\end{tabular}

Table 1: Chemical composition of Bi2 $\mathrm{Te} 3$ and Bi0.5Sb1.5Te3 electroplated films surfaces by Microprobe 

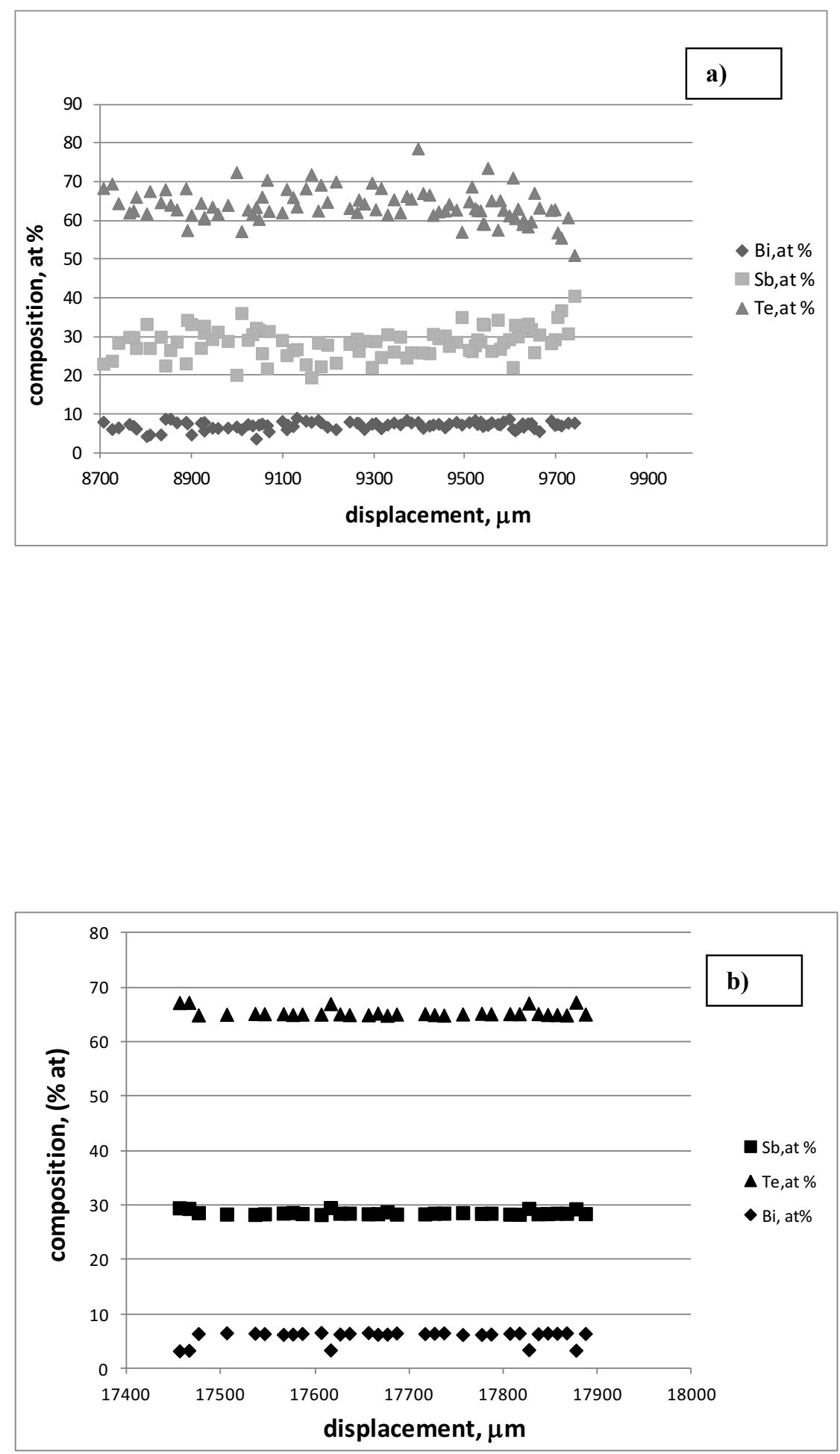

Fig. 8: Microprobe profiles of a) $\mathrm{Bi}_{0.5} \mathrm{Sb}_{1.5} \mathrm{Te}_{3}$ not annealed; b) $\mathrm{Bi}_{0.5} \mathrm{Sb}_{1.5} \mathrm{Te}_{3}$ annealed electroplated films surfaces. 


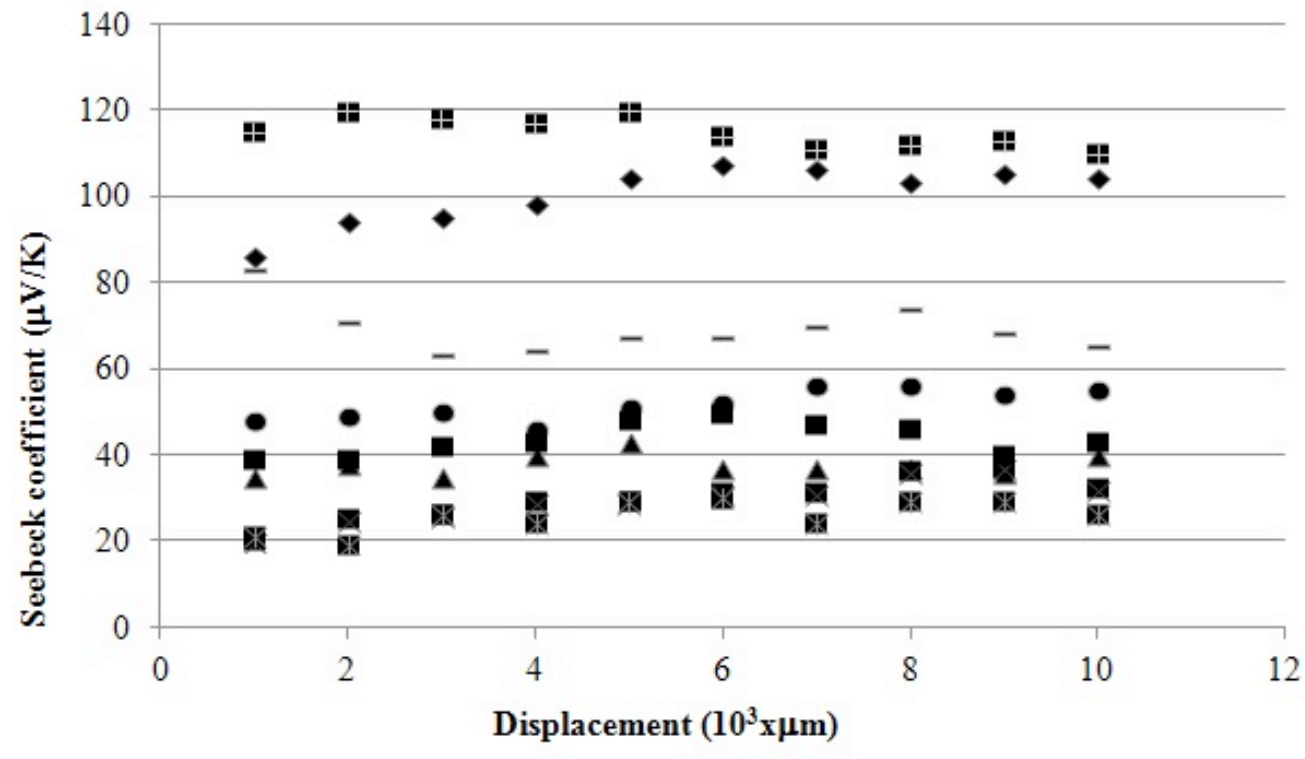

- Sample 1

- Sample 2

A Sample 3

- Sample 4

Sample 5

- Sample 6

- Sample 7

* Sample 8

Fig. 9: Seebeck coefficient profiles across the area of the $\mathrm{Bi}_{0.5} \mathrm{Sb}_{1.5} \mathrm{Te}_{3}$ electroplated films (Samples 1-8 have the same chemical composition of $\mathrm{Bi}_{0.5} \mathrm{Sb}_{1.5} \mathrm{Te}_{3}$. Any differences in Seebeck coefficient values are due to variations in electroplating processing).

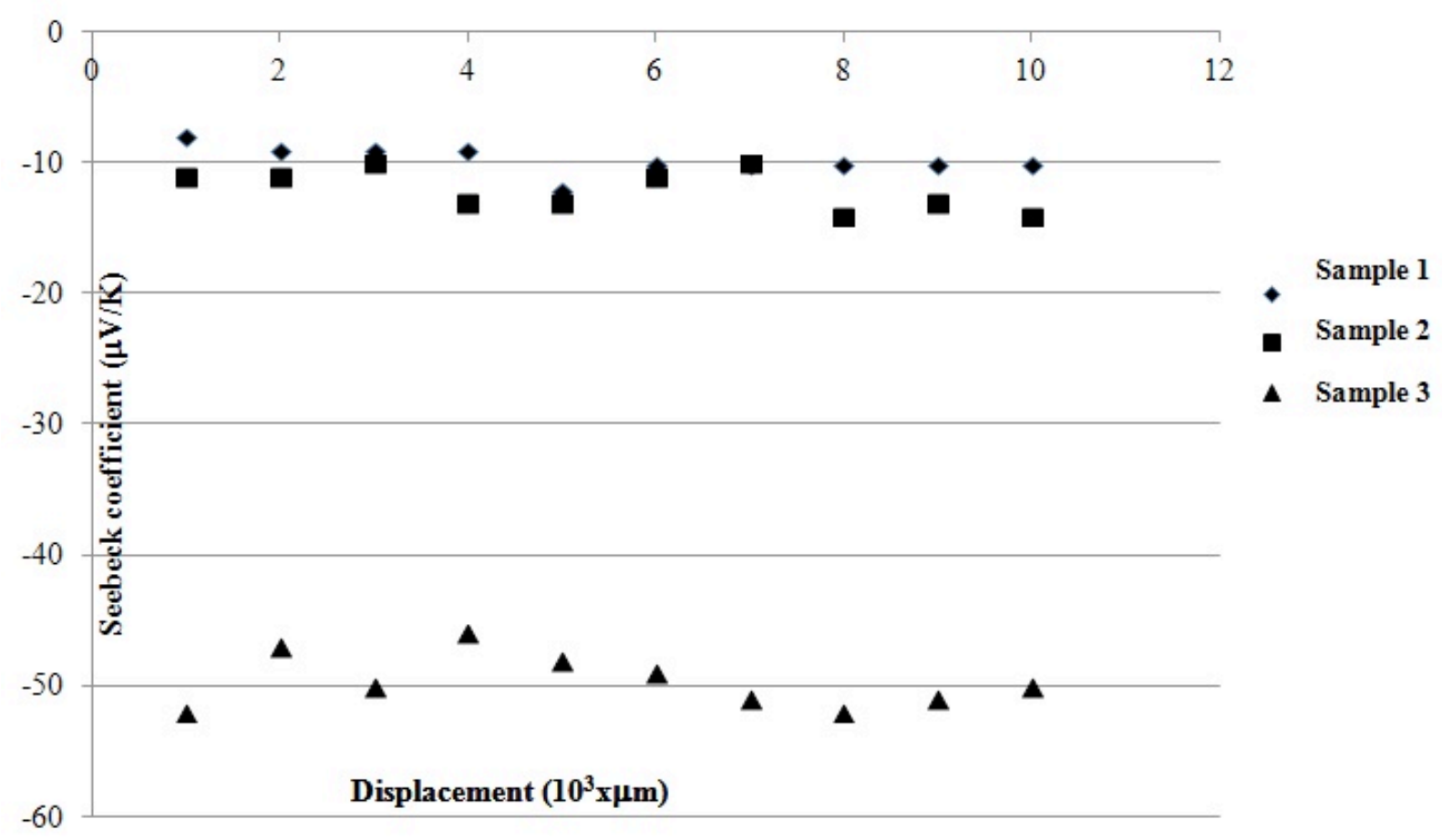

Fig. 10: Seebeck effect profiles across the area of the $\mathrm{Bi}_{2} \mathrm{Te}_{3}$ electroplated films (Samples 1-3 have the same chemical composition of $\mathrm{Bi}_{2} \mathrm{Te}_{3}$. Any differences in Seebeck coefficient values are due to variations in electroplating processing). 


\begin{tabular}{|l|lr|l|l|l|l|}
\hline $\begin{array}{l}\text { Chemical } \\
\text { composition }\end{array}$ & $\begin{array}{l}\text { Electrical } \\
\text { resistivity, } \rho \Omega \mathrm{cm}\end{array}$ & $\begin{array}{l}\text { Hall coefficient } \\
R_{H}{ }^{\prime} \mathrm{cm} / \mathrm{C}\end{array}$ & $\begin{array}{l}\text { Mobility } \\
\mu_{\mathrm{e},} \\
\mathrm{cm}^{2} / \mathrm{Vs}\end{array}$ & $\begin{array}{l}\text { Carrier } \\
\text { concentration, } \mathrm{cm}^{-3}\end{array}$ & Type \\
\hline $\mathrm{Bi}_{2} \mathrm{Te}_{3}$ & $\begin{array}{l}3.4 \times 10^{-5} \\
8.1 \times 10^{-5}\end{array}$ & to & $\begin{array}{l}-10^{-3} \text { to }-5.2 \times 10^{-} \\
4\end{array}$ & 18 to 35 & $\begin{array}{l}-6.5 \times 10^{21} \\
1.2 \times 10^{22}\end{array}$ & to - \\
\hline $\mathrm{Bi}_{0.5} \mathrm{Sb}_{1.5} \mathrm{Te}_{3}$ & $\begin{array}{l}7.7 \times 10^{-5} \\
1.6 \times 10^{-4}\end{array}$ & to & $10^{-3}$ to $10^{-4}$ & 1.4 to 22 & $1.7 \times 10^{21}$ to $5.6 \times 10^{22}$ & $\mathrm{p}$ \\
\hline
\end{tabular}

Table 2: Transport properties for $\mathrm{Bi}_{2} \mathrm{Te}_{3}$ and $\mathrm{Bi}_{0.5} \mathrm{Sb}_{1.5} \mathrm{Te}_{3}$ films

\begin{tabular}{|c|c|c|c|}
\hline $\begin{array}{l}\text { Seebeck coefficient } \\
\text { measured in this } \\
\text { manuscript for } \\
\text { raw/annealed } \mathrm{Bi}_{2} \mathrm{Te}_{3} \text {, } \\
\mu \mathrm{V} / \mathrm{K}\end{array}$ & $\begin{array}{l}\text { Examples of Seebeck } \\
\text { coefficient values for } \\
\text { bulk } \mathrm{Bi}_{2} \mathrm{Te}_{3}, \mu \mathrm{V} / \mathrm{K}\end{array}$ & $\begin{array}{l}\text { Seebeck coefficient } \\
\text { measured for measured } \\
\text { in this manuscript } \\
\text { raw/annealed } \\
\mathrm{Bi}_{0.5} \mathrm{Sb}_{1.5} \mathrm{Te}_{3, \mu} \mu \mathrm{V} / \mathrm{K}\end{array}$ & $\begin{array}{l}\text { Examples of } \\
\text { Seebeck coefficient } \\
\text { values for bulk } \\
\mathrm{Bi}_{0.5} \mathrm{Sb}_{1.5} \mathrm{Te}_{3, \mu \mathrm{V} / \mathrm{K}}\end{array}$ \\
\hline $\begin{array}{l}-52 \text { for raw film } \\
-60 \text { for annealed film }\end{array}$ & $\begin{array}{l}-231[59] \\
-210[60] \\
-170-220[61] \\
-225[1]\end{array}$ & $\begin{array}{l}120 \text { for raw film } \\
\sim 180 \text { for annealed film }\end{array}$ & $\begin{array}{l}180-190[60] \\
132-180[59]\end{array}$ \\
\hline
\end{tabular}

Table 3: Seebeck coefficient for $\mathrm{Bi}_{2} \mathrm{Te}_{3}$ and $\mathrm{Bi}_{0.5} \mathrm{Sb}_{1.5} \mathrm{Te}_{3}$ films compared with the values for bulk materials 


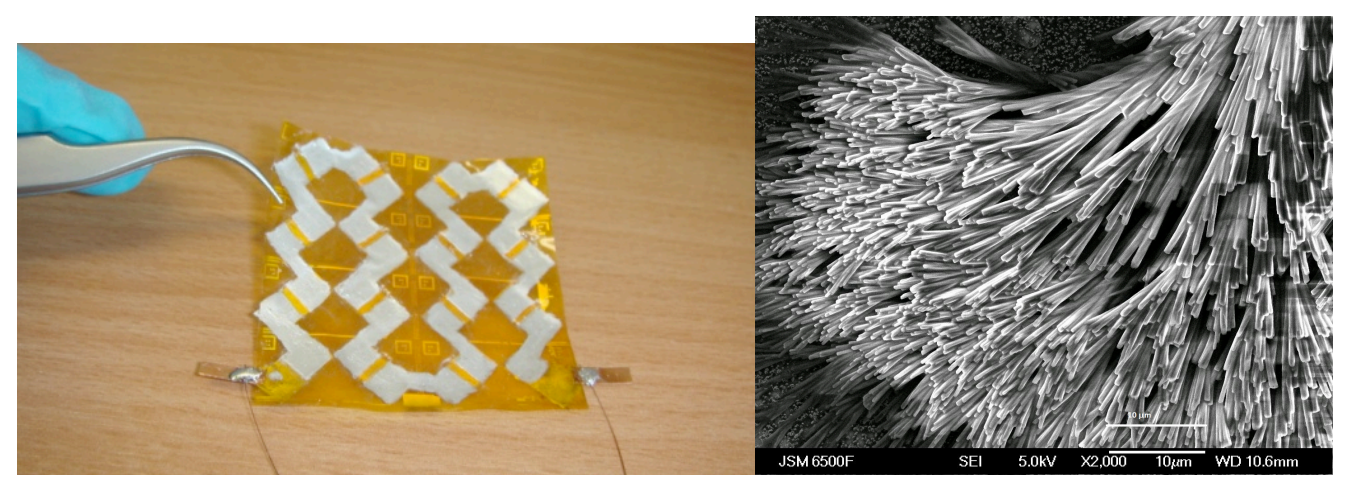

\section{$29 \mathrm{~mm}$}

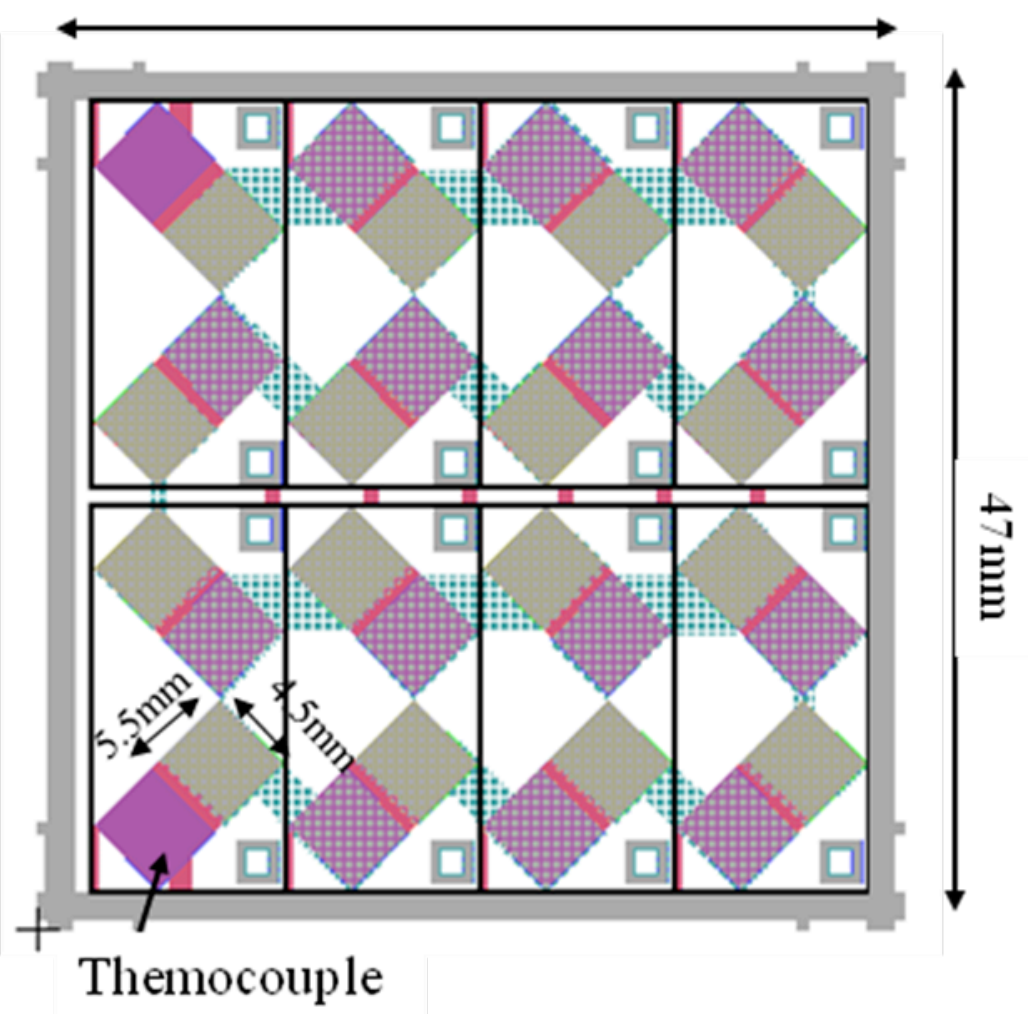

Fig. 11: a) Photograph of a nanostructured TE prototype device onto a polyimide flexible substrate; b) high density $5 \times 10^{9} \mathrm{Bi}_{0.5} \mathrm{Sb}_{1.5} \mathrm{Te}_{3}$ nanowires $/ \mathrm{cm}^{2}$ released from nanotemplate for microstructural characterisation ; c) schematic of the layout of the mask design for a nanostructured TE prototype 


\section{Figure legends}

Fig.1: Process flow of a thermoelectric microgenerator on a flexible substrate

Fig. 2: a) Operational principle of the Seebeck coefficients measurements; b) Picture of custom-made measurement unit

a)

b)

Fig. 3: SEM images of polyimide, $5 \times 10^{9}$ ions $/ \mathrm{cm}^{2}$ (Kapton $\mathrm{HN}, \sim 20 \mu \mathrm{m}$ thick), ion-track etched, $40 \mathrm{~min}$ in $\mathrm{H}_{2} \mathrm{O}_{2}\left(60^{\circ} \mathrm{C}\right)$ followed by a) 5 min and b) $7 \mathrm{~min}$ in $\mathrm{NaOCl}\left(60^{\circ} \mathrm{C}\right)$. The pores have diameters from 30 to $120 \mathrm{~nm}$.

a)

b)

Fig.4: a) SEM image of a cross section of $\mathrm{Bi}_{2} \mathrm{Te}_{3}$ nanowires deposited at $-0.2 \mathrm{~V}$ vs. SCE at room temperature into polyimide template; b) $\mathrm{Bi}_{2} \mathrm{Te}_{3}$ nanowires overgrowth structure

a)

b)

Fig.5: SEM images of $\mathrm{Bi}_{0.5} \mathrm{Sb}_{1.5} \mathrm{Te}_{3}$ nanowires liberated from Kapton foil by dissolving in NMP (N-methylpyrrolidone)/MEA (monoethanol-amine) (a) NMP/MEA compositions (wt $\%$ ) of 90/10, resulting in $6.9 \mu \mathrm{m}$ long nanowires; (b) NMP/MEA compositions (wt \%) of $30 / 70$ resulting in $20 \mu \mathrm{m}$ long nanowires.

Fig. 6: XRD of a) $\mathrm{Bi}_{2} \mathrm{Te}_{3}$ and b) $\mathrm{Bi}_{0.5} \mathrm{Sb}_{1.5} \mathrm{Te}_{3}$ nanowire composition by electroplating

Fig. 7: Helium microscope image of $\mathrm{Bi}_{0.5} \mathrm{Sb}_{1.5} \mathrm{Te}_{3}$ nanowires with hexagonal crystallographic structure

Table 1: Chemical composition of Bi2 $\mathrm{Te} 3$ and $\mathrm{Bi} 0.5 \mathrm{Sb} 1.5 \mathrm{Te} 3$ electroplated films surfaces by Microprobe 
Fig. 8: Microprobe profiles of a) $\mathrm{Bi}_{0.5} \mathrm{Sb}_{1.5} \mathrm{Te}_{3}$ not annealed; b) $\mathrm{Bi}_{0.5} \mathrm{Sb}_{1.5} \mathrm{Te}_{3}$ annealed electroplated films surfaces.

Fig. 9: Seebeck coefficient profiles across the area of the $\mathrm{Bi}_{0.5} \mathrm{Sb}_{1.5} \mathrm{Te}_{3}$ electroplated films (Samples 1-8 have the same chemical composition of $\mathrm{Bi}_{0.5} \mathrm{Sb}_{1.5} \mathrm{Te}_{3}$. Any differences in Seebeck coefficient values are due to variations in electroplating processing).

Fig. 10: Seebeck effect profiles across the area of the $\mathrm{Bi}_{2} \mathrm{Te}_{3}$ electroplated films (Samples 1-3 have the same chemical composition of $\mathrm{Bi}_{2} \mathrm{Te}_{3}$. Any differences in Seebeck coefficient values are due to variations in electroplating processing).

Table 2: Transport properties for $\mathrm{Bi}_{2} \mathrm{Te}_{3}$ and $\mathrm{Bi}_{0.5} \mathrm{Sb}_{1.5} \mathrm{Te}_{3}$ films

Table 3: Seebeck coefficient for $\mathrm{Bi}_{2} \mathrm{Te}_{3}$ and $\mathrm{Bi}_{0.5} \mathrm{Sb}_{1.5} \mathrm{Te}_{3}$ films compared with the values for bulk materials

Fig. 11: a) Photograph of a nanostructured TE prototype device onto a polyimide flexible substrate; b) high density $5 \times 10^{9} \mathrm{Bi}_{0.5} \mathrm{Sb}_{1.5} \mathrm{Te}_{3}$ nanowires $/ \mathrm{cm}^{2}$ released from nanotemplate for microstructural characterization; c) schematic of the layout of the mask design for a nanostructured TE prototype

\section{References}

1. D.M. ROWE Thermoelectrics Handbook Macro to Nano. 2006, ed. CRC Press Talor \&Francis, Boca Raton London New York; 2006.

2. http://www.tellurex.com/

3. http://micropelt.com/technology.php

4. L. D. HICKS, T.C. HARMAN, M.S. DRESSELHAUS, Appl. Phys. Lett. 63 (23) (1993) 3230

5 . L. D. HICKS, M.S. DRESSELHAUS, Physical Review B47(24) (1993), 16631

6. R. VENKATASUBRAMANIAN, E. SIIVOLA, T. COLPITTS, B. O'QUINN, NATURE 413 (2001), 597

7. E.A. HOFFMANN, H.A. NILSSON, J.E. MATTHEWS, N. NAKPATHOMKUN, A.I. PERSSON, L. SAMUELSON, H.LINKE, Nano lett. 9 (2) (2009), 779 
8. A.I. BOUKAI, Yu. BUNIMOVICH, TAHIR-KHELI, J-K. YU, W.A. GODDARD III, J.R. HEATH, Nature 451 (2008), 168

9. A.I. HOCHBAUM, R. CHEN, R.D. DELGADO, W. LIANG, E.C. GARNETT, M. NAJARIAN, A. MAJUMDAR, P. YANG, Nature 451 (2008), 163

10. YU. CHOONGHO, SHI. LI, YAO. ZHEN, LI DEYU, MAJUMDAR ARUNAVA, Nano Lett 5 (9) (2005), 1842

11. J. ZHOU, C. JIN, J.H. SEOL, X. LI, LI. SHI, Appl. Phys. Lett. 87 (2005), 133109-1

12. HO-KI LYEO, A. A. KHAJETOORIANS, SHI. LI, K.P. PIPE, R.J. RAM, ALI

SHAKOURI, C.K. SHIH, Science 303 (2004), 816

13. X. ZOU, X. CHEN, H. HUANG, Y. XU AND W. DUAN, Nanoscale, 7 (2015), 8776

14. N. WATANABE, J. KAWAMATA, N. TOSHIMA, Chem Lett. 33 (10) (2004), 1368

15. V.M. GOLTSMAN, V.A. KUDINOV, I.A. SMIRNOV Semiconducting thermoelectric materials based on $\mathrm{Bi}_{2} \mathrm{Te}_{3}, 1972$ ed. Moskow, Nauka

16. S. MADER, J.VAC.SCI.TECHNOL, 2 (1) (1965), 35

17. A. GIANI, F. PASCAL-DELANNOY, A. BOYER, A. FOUCARAN, M. GSCHWIND, P. ANCEY, Thin Solid Films 303 (1) (1997), 1

18. S. CHO, Y. KIM, A. DIVENERE, G.K. WONG, J.B. KETTERSON, AND J.R. MEYER, Appl. Phys. Lett. 75 (1999), 1401

19. X. XIAOCHUAN, C. LIDONG, W. CHUNFEN, Y. QIN AND F. CHUDE, J.Sol. State Chem. 178 (2005), 2163

20. W-L. WANG, C-C. WAN AND Y-Y. WANG , J. Phys. Chem. B 110 (2006), 12974

21. J.G. SNYDER, J.R. LIM, C-K. HUANG AND J.P. FLEURIAL, Nat. Mat. 2 (2003),528

22. CHEN LUNG CHENG, CHEN YUAN YANG P. C. LEE, C.T. CHEN, S. R. HARUTYUNYAN, S.J. LAI, C.D. CHEN, S.J. LIN, American Physical Society APS March Meeting (2008)

23. L. WOO, J. I. RAN, U. GO, SELE AND K. NIELSCH, Nat. Mat. 5 (2006), 741

24. B. YOO, F. XIAO, K.N. BOZHILOV, J. HERMAN, M.A. RYAN and N.V. MYUNG, Adv. Mat. 19 (2007), 296

25. M.E. TOIMIL MOLARES, N. CHTANKO, T.W.C. CORNELIUS, D. DOBREV, I.

ENCULESCU1, R.H. BLICK AND R. NEUMANN, Nanotech. (2004), S201 
26. E. KOUKHARENKO, X. LI, I. NANDHAKUMAR, M.J. TUDOR, S.P. BEEBY, B. SCHIEDT, C. TRAUTMANN, AND N.M.WHITE, IET letters 44(7) (2007), 500

27. M. RAUBER, I. ALBER, S. MULLER, R. NEUMANN, O. PICHT, C ROTH, A. SCHOKEL, Nanoletters 11 (2011), 2304

28. M LINDEBERG AND K.HJORT, Microsys. Technol. 10(8) (2004), 608

29. E. KOUKHARENKO, X. LI, I. NANDHAKUMAR, N. FRETY, S. P. BEEBY, D. COX, M. J. TUDOR, B. SCHIEDT, C. TRAUTMANN, A. BERTSCH, AND N M.WHITE, J. Micromech. Microeng. 18 (2008), 104015

30. E. KOUKHARENKO, J. KULESHOVA, M. FOWLER, M.J. TUDOR, D. O'CONNELL, J. PIKE, S.P. BEEBY, I NANDHAKUMAR, AND N.M. WHITE, Japanese Journal of Applied Physics (JJAP) 49( 6) (2010), 06GE07-1

31. YA. YANG, Z-H LIN, T. HOU, F.Zhang, Z.L. WANG, Nano Res., (2016) DOI $10.1007 / \mathrm{s} 12274-012-0272-8$

32. C. WAN, X, GU, F. DANG, T. ITOH , Y. WANG, H. SASAKI, M. KONDO, K. KOGA, M. KONDO, K. KOGA, K. YABUKI, G.J. SNYDER, R. YANG, K. KOUMOTO, Nature materials 14 (2015), 622

33. W. GLATZ, S. MUNTWYLER, C. HIEROLD, Sensors and Actuators A 132(2006), 337

34 A. YADAV, K.P. PIPE, M. SHTEIN, Journal of Power Sources 175 (2008), 909

35 L.M. GONCALVES, J.G. ROCHA, C. COUTO, P. ALPIUM, G. MIN, D.M. ROWE AND J.H. CORREIA, J Micromech. Microeng. 17 (S) (2007), 168

36. W. QU, M. PLOTNER AND W.J. FISCHER, J. Micromech. Microeng. 11 (2001), 146

37. L. FRANCIOSO, C. DE PASCAli, I. FARELla, C. MARTUCCI, P. CRETÌ, P. SICILIANO, A. PERRONE, IEEE SENSORS 2010 Conference, 747

38 . Y. DU, K.CAI, S. CHEN, H. WANG, S. Z. SHEN, R. DONELSON \& T. LIN, Nature scientific reports 5(2015), 6411, DOI: 10.1038/srep06411

39. E. KOUKHARENKO, X. LI, I NANDHAKUMAR, M.J. TUDOR, S.P. BEEBY, B. SCHIEDT, C. TRAUTMANN, AND N.M.WHITE, Proc. Power MEMS (2007), 145

40. X. LI, E KOUKHARENKO, I NANDHAKUMAR, M.J. TUDOR, S.P. BEEBY, AND N.M.WHITE, Phys. Chem. Chem. Phys. 11 (2009), 3584

41. B.W. WARD, J.A. NOTTE, AND N.P. ECONOMOU, Journal of Vacuum Science and Technology B 24(6) (2006), 2871

42. L. SCIPIONI, L. A. STERN, J. NOTTE, S. SIJBRANDIJ, AND B. GRIFFIN, Advanced Materials \& Processes 166 (2008), 27 
43. S.A. BODEN, A. ASADOLLAHBAIK, H.N. RUTT, D. M. BAGNALL, Scanning 33 (2011), 107

44. G. S. NOLAS, J.SHARP AND H. J. GOLDSMID Thermoelectrics: Basic Principles and New Materials Developments 2001, ed Springer series in materials science, Springer, New York 2001

\section{5. https://www.tcdirect.co.uk/}

46. SCHLESINGER, M. MORDECHAY PAUNOVIC Modern Electroplating 2011, The ECS Series of Texts and Monographs, ed 5 Wiley, 2011

47. Z. STARY, J. HORAK, M. STORDEUR, M. STOLZER, Journal of Physics and Chemistry of Solids 49 (1) (1988), 29

48. J. HORAK, K. CERMAK, L. KOUDELKA, Journal of Physics and Chemistry of Solids. 47 (8) (1986), 805

49. G. R. MILLER, CHE-YU LI, Journal of Physics and Chemistry of Solids 26 (1) (1965), 173

50. J. PRZYLUSKI, K. BORKOWSKI, Proc. of $4^{\text {th }}$ International Conference on Thermoelectric Energy Conversion (1982), 11

51. J. R. DRABBLE AND C. H.L. GOODMAN, Journal of physics and chemistry of solids $5(1-2)(1958), 142$

52. D. EYIDI D. MAIER, O. EIBL, M. WESTPHAL, Physica status solidi (a), 187 (2), (2001), 585

53. E. KOUKHARENKO N. FRETY, V. G SHEPELEVICH AND J.C. TEDENAC, J. of Cryst. Growth. 222 (4) (2001), 773

54 V.L. NALETOV AND D.R. BAZHENOV, Proc. of the Third International Workshop on Thermoelectric Materials 22 (1992)

55. T. CAILLAT, M.CARLE, D. PERRIN, H. SCHERRER, S.SCHERRER, J. Phys. Chem. Solids 53(2) (1992), 227

56. S I. MUDRY, Journal of Alloys and Compounds 267 (1-2) (1998), 100

57. V. RICHOUX, S. DILIBERTO, AND C. BOULANGER, Journal of Electronic materials 39(9) (2010), 1914

58. V. G.SHEPELEVICH, Inorganic materials. 32 (6) (1996)

59. CHENG-LUNG CHEN, YANG-YUAN CHEN, SU-JIEN LIN, J.C. HO, PING-CHUNG

LEE, CHII-DONG CHEN, AND S. R. HARUTYUNYAN, J. Phys. Chem. C 114 (2010) 3385 
60. SU-KYUM LIM, MIN-YOUNG KIM, TAE-SUNG OH, Thin Solid Films 517 (2009) 4199 